\title{
A GERAÇÃO QUÍMICA DE VAPOR EM ESPECTROMETRIA ATÔMICA
}

\section{Iracema Takase}

Departamento de Química Analítica, Instituto de Química, Universidade Federal do Rio de Janeiro, Av. Brigadeiro Trompowsky, s/n, CT, Ilha do Fundão, 21949-900 Rio de Janeiro - RJ

\section{Hugo Borges Pereira e Aderval S. Luna}

Departamento de Química Analítica, Instituto de Química, Universidade do Estado do Rio de Janeiro, R. São Francisco Xavier, 524, 20550-013 Rio de Janeiro - RJ

Patrícia Grinberg e Reinaldo Calixto de Campos*

Departamento de Química, Pontifícia Universidade Católica do Rio de Janeiro, Rua Marquês de São Vicente, 225, 22453-900

Rio de Janeiro - RJ

Recebido em 17/9/01; aceito em 29/5/02

\begin{abstract}
CHEMICAL VAPOR GENERATION IN ATOMIC SPECTROMETRY. The historical development of atomic spectrometry techniques based on chemical vapor generation by both batch and flow injection sampling formats is presented. Detection via atomic absorption spectrometry (AAS), microwave induced plasma optical emission spectrometry (MIP-OES), inductively coupled plasma optical emission spectrometry (ICP-OES), inductively coupled plasma mass spectrometry (ICP-MS) and furnace atomic nonthermal excitation spectrometry (FANES) are considered. Hydride generation is separately considered in contrast to other methods of generation of volatile derivatives. $\mathrm{Hg}$ - CVAAS (cold vapor atomic absorption spectrometry) is not considered here. The current state-of-the-art, including extension, advantages and limitations of this approach is discussed.
\end{abstract}

Keywords: chemical vapor generation; atomic spectrometry; batch and flow injection.

\section{INTRODUÇÃO}

O sucesso da espectrometria atômica depende, freqüentemente, do procedimento de introdução da amostra, sendo que o modo mais comum baseia-se na formação de um aerossol líquido, por meio de nebulizadores pneumáticos. Esses dispositivos são de operação simples e conveniente e, por isso mesmo, amplamente utilizados. Entretanto, menos de $10 \%$ da solução introduzida é transformada em aerossol útil, sendo sua maior parte, portanto, descartada. Além disso, dificuldades com esses nebulizadores surgem quando são usadas soluções muito viscosas ou com alto teor salino ou, ainda, quando se dispõe tão somente de micro-volumes de amostra ${ }^{1}$.

Uma alternativa que se apresenta é a transformação da espécie de interesse em um composto volátil, e seu posterior transporte para a célula de atomização. Quando esta transformação se faz por meio de uma reação química, o processo é conhecido como geração química de vapor. A geração eletroquímica também é citada, embora menos freqüentemente ${ }^{2-7}$. Dois trabalhos podem ser considerados como marcos na geração química de vapor: no primeiro, Hatch e Ott ${ }^{8}$ inauguraram a técnica hoje conhecida como "de vapor frio", embora se deva citar os trabalhos anteriores de Poluektov et al. ${ }^{910} \mathrm{Na}$ técnica do vapor frio, o íon mercúrico contido numa solução da amostra é reduzido a mercúrio elementar e assim carreado por uma corrente de gás (ar, $\mathrm{N}_{2}$ ou Ar), borbulhada através da solução, para a célula de absorção; ou seja, o vapor formado pela reação já é o próprio vapor atômico. $\mathrm{O}$ segundo marco na geração de vapor é o trabalho de Holak ${ }^{11}$, onde o arsênio foi reduzido a arsina pela adição, à amostra ácida, de Zn metálico, e esta transportada para a chama de um aparelho de absorção atômica. O ganho em sensibilidade observado resulta da maior eficiência de transporte do analito, em comparação com a nebulização pneu-

*e-mail: rccampos@rdc.puc-rio.br mática, uma vez que toda a arsina formada pode, em princípio, alcançar o atomizador, carreada por um fluxo de argônio ou nitrogênio e também pelo próprio gás hidrogênio gerado na reação. Entretanto, a atomização do arsênio usando chama convencional apresenta dificuldades, devido à forte absorção da chama em comprimentos de onda abaixo de $200 \mathrm{~nm}$, onde encontram-se as linhas mais sensíveis do arsênio ${ }^{12}$. Assim, Chu et al. ${ }^{13}$ relataram, três anos depois, um procedimento alternativo, onde a arsina produzida era carreada pelo argônio não mais para a chama, mas para uma célula de absorção formada por um tubo T, de quartzo, eletricamente aquecido, postado ao longo do caminho ótico do equipamento de absorção atômica. Assim, a absorção de parte da radiação da fonte primária pela chama era evitada, aumentando a intensidade da radiação que alcançava o detector, contribuindo, junto com o maior tempo de residência do vapor na célula de absorção, para uma melhoria considerável no limite de detecção. Uma vez que a espécie volátil formada é uma molécula, esta deve ser ainda atomizada na célula de absorção e, daí, a importância de seu aquecimento. Entretanto, a adição de metais, como $\mathrm{Zn}, \mathrm{Al}$ ou $\mathrm{Mg}$, a soluções ácidas levava à formação de apenas poucos hidretos voláteis (basicamente, $\mathrm{AsH}_{3}$ e $\mathrm{SeH}_{2}$ ), restringindo a aplicação da técnica, ao mesmo tempo em que problemas de reprodutibilidade e de altos brancos eram relatados ${ }^{14}$. Esta situação foi alterada quando, ainda em 1972, Braman et $a l .{ }^{15}$ relataram o uso de soluções redutoras de tetrahidroborato de sódio $\left(\mathrm{NaBH}_{4}\right)$, estabilizadas em meio alcalino, para a determinação de arsênio e antimônio. Os derivados de arsênio e antimônio eram convertidos a $\mathrm{AsH}_{3}$ e $\mathrm{SbH}_{3}$, respectivamente, sendo a arsina e a estibina purgadas da solução pelo argônio, passadas através de um tubo dessecante com $\mathrm{CaSO}_{4}$, medindo-se, então, a emissão com um detector de descarga de corrente contínua. O uso do tetrahidroborato de sódio ampliou o número de elementos determináveis por geração química de vapor (no caso, ainda, somente hidretos voláteis), que passou a incluir, também o $\mathrm{Bi}, \mathrm{Ge}, \mathrm{Pb}, \mathrm{Sb}, \mathrm{Se}, \mathrm{Sn}$ e $\mathrm{Te}^{14}$. Atualmente, a determinação tem sido estendida para incluir o $\mathrm{P}^{16}, \mathrm{Tl}^{17}, \mathrm{In}^{18} \mathrm{e} \mathrm{Cd}^{19-21}$, 
sendo que Luna et $a^{22,23}$ mostraram que os elementos $\mathrm{Cu}, \mathrm{Au}, \mathrm{Ag}$ e $\mathrm{Zn}$ também podem ser determinados por HGAAS. Limites de quantificação ao nível de $\mu \mathrm{g} \mathrm{L}{ }^{-1}$ podem ser alcançados, normalmente suficientes para análise de amostras de interesse ambiental, clínico ou tecnológico.

Entre as principais vantagens e características da técnica de geração química de vapor estão: (i) como, geralmente, apenas o analito forma a espécie volátil, este passa a ser o único componente da amostra a ser transferido para a célula de atomização, ou seja, há a sua separação prévia da matriz, ocorrendo a atomização em um ambiente mais livre de concomitantes, evitando as possíveis interferências que poderiam vir a ser por eles aí causadas; (ii) é um sistema de introdução da amostra mais eficiente do que aqueles baseados na nebulização pneumática convencional, sendo que o transporte do vapor químico formado, embora dependendo do rendimento da reação, da eficiência da purga e do transporte ao atomizador, pode atingir cerca de $100 \%$; (iii) apresenta melhores limites de detecção, pois a maior eficiência de transporte leva à maior sensibilidade e daí a melhores limites de detecção; ao mesmo tempo, o confinamento do vapor atômico no volume definido pela célula de quartzo aumenta a densidade de átomos no caminho ótico, assim como seu tempo de residência e a eficiência de atomização pode alcançar $100 \%$; (iv) a leitura pode se dar por qualquer dos métodos de espectrometria atômica, absorção, emissão atômica, ICP-MS; (v) pode ser acoplada a sistemas que exploram a especiação e (vi) é passível de automação ${ }^{1}$.

Por outro lado, entre suas limitações podem-se incluir: (i) a suscetibilidade a interferências por concomitantes existentes na solução de leitura, que possam impedir a reação de geração de vapor, ou sua purga eficiente da solução; (ii) a cinética de geração de vapor pode ser afetada por fatores físicos associados à solução (densidade, viscosidade, volume, etc), de tal modo que, em alguns casos, pode ser necessário um dispositivo de coleta antes da introdução das espécies voláteis na fonte ou no atomizador, para compensar essas influências; (iii) o pH e as concentrações dos reagentes podem ser críticos para alguns elementos e (iv) os estados de oxidação ou a forma do analito podem ser $\operatorname{críticos}^{12,24}$.

\section{A GERAÇÃO DE HIDRETOS}

\section{A reação de geração de hidretos voláteis}

O processo de determinação espectrométrica por geração química de vapor pode ser dividido em três etapas: a geração da espécie volátil, ou seja, a reação química propriamente dita, o transporte da espécie volátil para a célula de atomização (que inclui também sua expulsão da solução) e a atomização. Focando-se, inicialmente, a geração da espécie volátil, e aí apenas a produção de hidretos, vários reagentes foram sugeridos. Primeiramente, foi utilizada a adição de um metal em pó à amostra ácida, gerando $\mathrm{H}_{2}$, a exemplo da reação de Gutzeit. Foram empregados zinco metálico/ $\mathrm{HCl}$, suspensão de alumínio/HCle

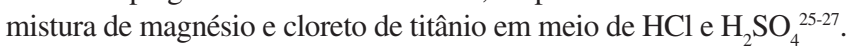
Entretanto, estes sistemas redutores apresentavam várias limitações: apenas o As, Se e $\mathrm{Sb}$ eram reduzidos aos seus hidretos; os brancos eram muito altos, pela dificuldade em serem obtidos metais com suficiente grau de pureza, e as leituras eram pouco reprodutíveis. Mais adequado, portanto, mostrou-se o uso do $\mathrm{NaBH}_{4}{ }^{15,25-27}$, sendo a redução efetivada de acordo com as seguintes reações:

$$
\begin{aligned}
& \mathrm{NaBH}_{4}+\mathrm{HCl}+3 \mathrm{H}_{2} \mathrm{O} \rightarrow \mathrm{H}_{3} \mathrm{BO}_{3}+\mathrm{NaCl}+8 \mathrm{H}^{\circ} \\
& 8 \mathrm{H}^{\circ}+\mathrm{X}^{\mathrm{m}+} \rightarrow \mathrm{XH}_{\mathrm{n}}+\mathrm{H}_{2 \text { (excesso) }}
\end{aligned}
$$

onde $\mathrm{m}$ pode ser ou não igual a $\mathrm{n}$ e $\mathrm{X}$ é o elemento de interesse.

$\mathrm{O} \mathrm{NaBH}_{4}$ foi inicialmente utilizado sólido, na forma de drágea.
Entretanto, a introdução de um sólido no meio reacional representa alta concentração localizada de reagente, o que é indesejável (supersaturação relativa), gerando sinais pouco reprodutivos e de perfil irregular. Uma solução de $\mathrm{NaBH}_{4}$ em meio alcalino (de modo a estabilizá-la), recém-preparada, é mais eficiente e a maior reprodutibilidade observada associa-se à reação em meio homogêneo, com cinética de reação mais definida, além de possibilitar a automação. A concentração do tetrahidroborato de sódio deve ser otimizada para o elemento de interesse, assim como para o equipamento utilizado. Várias concentrações de $\mathrm{NaBH}_{4}$ são recomendadas $(0,5$ a $10 \% \mathrm{~m} / \mathrm{v}$, para sistemas em batelada ou 0,3 a $1 \% \mathrm{~m} / \mathrm{v}$, para sistemas em fluxo), estabilizadas em $\mathrm{KOH}$ ou $\mathrm{NaOH}, 0,1$ a $2 \%$ m/ $/ \mathrm{v}^{24}$. Este redutor é hoje o mais amplamente empregado para a geração de hidretos, tanto para sistemas em batelada, como por injeção em fluxo, qualquer que seja o método posterior de detecção. A rápida reação entre o $\mathrm{NaBH}_{4}$ e o $\mathrm{HCl}$ pode gerar uma espuma indesejável, particularmente quando fluidos ou digeridos biológicos são analisados. Neste caso, é útil utilizar um anti-espumante ${ }^{28}$.

\section{O transporte das espécies voláteis: transporte direto versus coleta}

Pode-se dividir os processos de transporte em dois modos: a transferência direta e a coleta. No modo de transferência direta, as espécies voláteis são transportadas diretamente para o atomizador. No modo de coleta, as espécies voláteis vão sendo retidas em uma armadilha, postada entre o frasco de reação e o atomizador, até que o processo tenha se completado. Posteriormente, as espécies assim retidas são liberadas e transportadas para a célula de leitura ${ }^{14}$. O modo de coleta foi, inicialmente, o mais freqüentemente empregado, pois o redutor metal-ácido utilizado era relativamente lento, podendo decorrer alguns minutos até que a reação se completasse. Daí ser vantajoso concentrar previamente a espécie volátil, para só depois liberá-la e transportá-la para a célula de leitura, no mais curto espaço de tempo possível, pois se obtinha um sinal maior e mais reprodutivo. Deve ser enfatizado que, quando a adição do $\mathrm{NaBH}_{4}$ à amostra ácida passou a ser empregada, a necessidade de se coletarem as espécies tornou-se muito menos premente, dada a rapidez, agora observada, da reação de redução. Portanto, atualmente, os métodos de transferência direta são os mais freqüentemente utilizados. A coleta passou a estar relacionada a procedimentos de pré-concentração, e não à necessidade de compensar efeitos cinéticos de baixas velocidades de reação.

No gerador de coleta, o vapor pode ser coletado em tubo fechado, sob pressão (coleta por pressão) ${ }^{15,26-29}$ ou em tubo U imerso em nitrogênio líquido (coleta com armadilha a frio). Nele, os hidretos são capturados ${ }^{24}$, mas não ${ }^{30-31}$ o hidrogênio. Também é possível a captura do hidreto gerado em uma solução absorvente, que pode ser de $\mathrm{AgNO}_{3}{ }^{31}, \mathrm{HgCl}_{2}-\mathrm{H}_{2} \mathrm{SO}_{4}-\mathrm{KMnO}_{4}{ }^{32}, \mathrm{Ag}$-DDTC-efedrina ${ }^{33}, \mathrm{KI}_{2}{ }_{2}{ }^{34-35}$, $\mathrm{Ce}(\mathrm{IV})-\mathrm{KI}^{36,37}$ ou I $\mathrm{I}_{2}^{38}$. Nesse caso, porém, o elemento será determinado por absorção atômica com chama, na solução de captura. Recentemente, sugeriu-se ${ }^{39}$ a captura do hidreto gerado em uma armadilha quente, simplesmente formada envolvendo-se uma parte da haste do tubo $\mathrm{T}$ de quartzo com uma resistência, aquecida a cerca de $350{ }^{\circ} \mathrm{C}$. O hidreto é aí decomposto, retido e pré-concentrado, sendo posteriormente liberado pelo aquecimento da haste a $900{ }^{\circ} \mathrm{C}$.

A técnica da coleta in situ ${ }^{14}$ é uma variante que acopla um gerador de espécie volátil (batelada ou fluxo) com o forno de grafite. O forno de grafite é usado para recolher e, em seguida, atomizar a espécie volátil. A coleta ocorre na parede interna do tubo de grafite ou na plataforma lá postada, podendo ou não suas superfícies terem sido previamente tratadas por um modificador. Garante-se, assim, não apenas a separação da matriz e uma atomização livre de interferências, como também a possibilidade de pré-concentração, já que 
todo o analito presente em grandes volumes de amostra pode ser introduzido e retido no forno, previamente ao ciclo de leitura, levando a um aumento considerável do poder de detecção relativo, como resultado da pré-concentração in situ. No caso específico do germânio, para o qual a eficiência de atomização no tubo de quartzo é extremamente baixa, este procedimento permite um expressivo ganho também por aumentar a eficiência do processo de atomização. Olhandose do ponto de vista da técnica de forno de grafite, a atomização é realizada em um ambiente livre da matriz, minimizando-se interferências. Nada impede que a coleta in situ no forno de grafite seja associada a leituras multielementares, neste caso pela geração simultânea e transporte de diferentes hidretos a equipamentos multielementares de forno de grafite, e de fornos de grafite acoplados a unidades de ICP-OES, ICP-MS ou, ainda, ao FAPES ${ }^{40}$.

A estabilidade do hidreto é de fundamental importância para a escolha do procedimento de transferência, já que certos métodos de coleta não podem ser usados para hidretos instáveis ${ }^{41}$. A desvantagem dos procedimentos de coleta/pré-concentração é o alto tempo consumido (alguns minutos por leitura) e o risco de contaminação. Estas dificuldades se fazem sentir na sua baixa popularidade, quando comparado com o procedimento de transferência direta ${ }^{14,41}$.

\section{Atomização e detecção}

Diferentes técnicas de espectrometria atômica têm sido acopladas com a geração química de vapor: absorção atômica (AAS), fluorescência atômica (AFS), emissão atômica por plasma induzido por microondas (MIP-OES), emissão ótica por plasma indutivamente acoplado (ICP-OES), espectrometria de massa com fonte de plasma indutivamente acoplado (ICP-MS) e emissão ótica em forno com excitação não térmica (FANES). A mais popular tem sido a espectrometria de absorção atômica, tendo em vista que os espectrômetros de absorção atômica encontram-se disponíveis na maioria dos laboratórios.

\section{Espectrometria de absorção atômica (AAS)}

\section{Chama}

Holak $^{11}$, na sua primeira aplicação da geração de hidretos, usou uma chama ar-acetileno estequiométrica, suportada em um queimador com três ranhuras, como atomizador. A chama ar-acetileno foi muito usada no início do desenvolvimento desta técnica, mas foi logo trocada pela chama de pressão argônio-hidrogênio (usualmente chamada chama de difusão argônio-hidrogênio $)^{26}$. O uso deste tipo de chama para a determinação de As em solução aquosa foi descrito por Kahn e Schallis ${ }^{42}$. Dalton e Malanoski ${ }^{43}$ introduziram a arsina (juntamente com o hidrogênio produzido na reação), diretamente em uma chama ar-hidrogênio-argônio e Fernandez e Manning ${ }^{44}$ coletaram a arsina em um balão, antes de liberá-la nesta mesma chama. Desde então, esta chama relativamente fria e de baixo fundo, suportada em um queimador convencional, foi a mais usada, junto com a chama ar-nitrogênio-hidrogênio ${ }^{45,46}$. As chamas de difusão, entretanto, são inferiores a outros atomizadores, pois a sensibilidade alcançada é menor, devido à pronunciada diluição do hidreto nos gases da chama, além da alta absorção de fundo e "ruído", que afetam o limite de detecção. Estes fatores contribuíram para que, enquanto chamas foram utilizadas como atomizadores, a técnica de geração de hidretos não alcançasse grande aceitação ${ }^{47}$.

\section{Atomização em tubo de quartzo aquecido externamente}

Chu, Thompson e Thomerson ${ }^{13,48}$ foram os primeiros a utilizar, como atomizador, um tubo de quartzo aquecido externamente na HGAAS. O aquecimento foi realizado tanto por uma chama ar- acetileno $^{48}$ como eletricamente ${ }^{13}$, tendo sido determinados As, Bi, $\mathrm{Ge}, \mathrm{Pb}, \mathrm{Sb}, \mathrm{Se}, \mathrm{Sn}$ e Te, já usando o $\mathrm{NaBH}_{4}$ como redutor. Desde então, este tipo de atomizador tornou-se o mais popular. O desenho consiste de um tubo T, alinhado no caminho ótico, com o braço central servindo de passagem ao hidreto e ao gás carreador para o interior da parte aquecida do tubo. O aquecimento é externo, realizado por uma chama ou através de uma manta resistora que o envolve. As duas saídas do tubo são simplesmente abertas, ou fechadas com janelas óticas. Se fechadas, dois pequenos braços para a saída dos gases são fundidos próximos aos seus extremos. Para prevenir a queima de hidrogênio nas saídas do tubo, o que provocaria sinais de fundo, pode-se injetar um fluxo auxiliar de gás inerte nas entradas auxiliares ${ }^{26,48}$, deixar as extremidades do tubo sem aquecimento e isoladas ${ }^{44-50}$, ou ainda envolvê-las com anéis de grafite ${ }^{51,52}$, para forçar a perda de calor. Para a melhor sensibilidade, é necessária uma concentração mínima de oxigênio no interior do atomizador, conforme será discutido adiante. Esta concentração depende da natureza do hidreto e da temperatura da célula de atomização: quanto maior a temperatura, menor a concentração de oxigênio necessária. Em menores temperaturas, o oxigênio, geralmente já presente no sistema como um contaminante, pode não ser suficiente para alcançar a sensibilidade ótima e, então, pode ser necessário um aporte extra deste gás ${ }^{53}$. Existe um efeito marcante do estado da superfície interna do tubo de quartzo na sensibilidade ${ }^{54}$, evidenciado por uma deterioração gradual de sensibilidade e/ou precisão. O desempenho ótimo pode ser mantido pela lavagem periódica do tubo de quartzo com solução de HF $10 \%$ v/v, mas o polimento da superfície interna do atomizador com alumínio foi também sugerido ${ }^{55}$. As vantagens deste atomizador em relação à chama são a eliminação da absorção de fundo e ruído a ela inerentes, e maior sensibilidade, devido ao confinamento e maior tempo de residência da nuvem atômica no caminho ótico, levando, assim, a limites de detecção da ordem do sub ng $\mathrm{L}^{-1}$.

A comparação entre os dois métodos de aquecimento do tubo (chama versus elétrico) revela que o aquecimento elétrico é preferível, uma vez que leva a um aquecimento mais homogêneo do tubo, sem gradientes de temperatura, permitindo maior reprodutibilidade das leituras. Ao mesmo tempo, a temperatura pode ser controlada e ajustada de acordo com o analito. Nos tubos aquecidos externamente por uma chama ar-acetileno, a diferença de temperatura entre a parte inferior e a superior do tubo alcança até $300{ }^{\circ} \mathrm{C}^{14}$.

\section{Atomização em tubo com chama interna}

Diferentes modificações no tubo de quartzo têm sido descritas na literatura. Numa das possibilidades, o tubo de quartzo não é aquecido, mas o excesso de hidrogênio gerado no frasco de reação é utilizado não só para carrear o hidreto ao tubo de quartzo, mas também para suportar uma chama $\mathrm{O}_{2}-\mathrm{H}_{2}$, formada na confluência da haste com a parte principal do tubo $\mathrm{T}$, utilizando o auxílio de uma pequena quantidade de oxigênio introduzida por um braço lateral. A atomização do hidreto dá-se nesta chama interna. Este sistema foi descrito pela primeira vez por Siemer ${ }^{56}$ e seu modelo, combinado com chama oxigênio-hidrogênio ${ }^{57}$ ou ar-hidrogênio ${ }^{58}$, foi adotado por outros autores, sem ou com algumas modificações ${ }^{53,57,59-66}$. Matousek et al. ${ }^{67,68}$ propuseram um tubo de quartzo com micro-chama múltipla para a determinação de As, Se e Sb. Para estes elementos, o tubo proposto melhorou as figuras de mérito (sensibilidade, faixa linear de calibração) e ampliou o limite de tolerância para os interferentes de atomização em uma ordem de grandeza, quando comparado com o tubo de quartzo convencional. Outra variante foi descrita por Grinberg et al. ${ }^{69}$. Um tubo T com orifícios na sua parte inferior é aquecido por uma chama ar-acetileno e, assim, partes dos gases da chama penetram no seu interior. A temperatura interna al- 
cança então valores de até $1500{ }^{\circ} \mathrm{C}$, permitindo a atomização dos hidretos. Os autores verificaram, neste caso, uma significativa redução da interferência mútua entre elementos formadores de hidretos.

\section{Atomização em forno de grafite}

O primeiro trabalho utilizando a atomização do hidreto no forno de grafite foi realizado em $1974^{70}$; desde então, vários autores têm utilizado o forno de grafite para atomização de hidretos ${ }^{14,71}$. Os procedimentos podem ser divididos em dois: a atomização direta e aquela precedida da captura in situ do hidreto no forno, com posterior atomização através de um programa de temperatura previamente definido. $\mathrm{O}$ procedimento para atomização direta assemelha-se àquele que utiliza o tubo aquecido externamente, apenas que o tubo não é de quartzo, mas de grafite. Ou seja, o hidreto é transferido diretamente do frasco de reação para o forno, o qual já está pré-aquecido a uma temperatura superior a $2200{ }^{\circ} \mathrm{C}^{66}$, suficiente para que se dê a atomização.

O primeiro uso da técnica de captura in situ foi relatado por Lee ${ }^{72}$. Desde então, foram publicados vários trabalhos ${ }^{73-76}$, inclusive com a adição prévia à captura de hidretos, de modificadores, permanentes ou não ${ }^{76-84}$. Estudos de especiação também são relatados ${ }^{85}$.

A sensibilidade na atomização direta no forno de grafite é, geralmente, menor do que na coleta in situ ou no uso de tubos T, de quartzo, o que se deve às menores dimensões dos tubos de grafite dos equipamentos comerciais e às altas temperaturas de atomização, que diminuem o tempo de residência dos átomos livres e, conseqüentemente a sensibilidade ${ }^{14}$. Deve-se considerar, ainda, a possibilidade de perda de algum hidreto nas partes frias do sistema, como superfícies metálicas e de grafite ${ }^{86}$.

\section{Espectrometria de fluorescência atômica (AFS)}

Thompson ${ }^{87}$ estudou a determinação de As, Sb, Se e Te por redução com $\mathrm{NaBH}_{4}$ e subseqüente detecção dos hidretos por AFS, com atomização em uma chama de hidrogênio-argônio, mantida em um tubo Pyrex, tendo sido a fluorescência atômica produzida por uma lâmpada de descarga sem eletrodos modulada ${ }^{12}$. Tsujii e Kuga ${ }^{88}$, determinando As, parecem ter sido os primeiros a relatar o uso de espectrômetros de fluorescência atômica não dispersivos na geração de hidretos. Foi usado um fotomultiplicador, insensível para radiação acima de 360 nm; Zn-HCl foi o sistema redutor e a atomização deu-se em uma chama de hidrogênio-argônio ${ }^{12}$. Nakajara e colaboradores $^{1,12}$ determinaram $\mathrm{As}, \mathrm{Bi}, \mathrm{Sb}, \mathrm{Se}$ e Te fazendo uso de um sistema AFS não dispersivo acoplado com a técnica de geração de hidretos. Na determinação de As, os autores verificaram que a chama hidrogênio-argônio leva a uma sensibilidade duas vezes maior do que a chama de hidrogênio-nitrogênio, em virtude de sua temperatura ser mais alta. Também foi confirmada a melhoria na sensibilidade de, pelo menos, uma ordem de grandeza para os instrumentos não dispersivos em comparação com um sistema dispersivo, quando utilizados na determinação de $\mathrm{As}, \mathrm{Bi}, \mathrm{Se}$ e $\mathrm{Te}^{12}$.

A técnica da fluorescência atômica oferece grandes vantagens em termos de linearidade e níveis de detecção, o que tem melhorado em função da qualidade das lâmpadas empregadas como fontes de excitação. Suas limitações, como espalhamento, supressão da fluorescência e emissão de fundo, dependem dos níveis de impurezas das amostras, mas a separação analito-matriz, inerente à geração de hidretos, favorece sua associação à detecção por fluorescência atômica ${ }^{89}$.

\section{Espectrometria de emissão ótica}

A técnica mais comumente utilizada para a introdução de uma solução de amostra em equipamentos com fonte de plasma baseia-se na injeção de um aerossol líquido, gerado por um nebulizador pneumático. Entretanto, alguns elementos, inclusive aqueles formadores de hidretos, os quais freqüentemente estão presentes nas amostras de interesse em concentrações muito baixas para serem assim determinados, mesmo com nebulização ultra-sônica ${ }^{12}$. Para esses elementos, sua introdução na forma de hidretos torna-se uma alternativa atraente, pois o potencial de ganho na sensibilidade é proporcional à razão entre as eficiências de transporte dos dois sistemas, ou seja, 1 a $3 \%$ para a nebulização pneumática e até $100 \%$ no caso da geração de hidretos. Assim, Thompson et al. ${ }^{90,91}$ relataram o uso da geração de hidretos para a determinação de As, Bi, Se e Te por ICP-OES, tendo sido os hidretos continuamente gerados pela reação com o $\mathrm{NaBH}_{4}$, introduzidos diretamente no plasma e os elementos detectados simultaneamente. Deste modo, os limites de detecção melhoraram em, no mínimo, uma ordem de grandeza em relação à nebulização convencional.

Um problema inerente à geração de hidretos, que resultou na demora de sua associação, com sucesso, ao ICP, é a extinção do plasma pelos subprodutos $\left(\mathrm{H}_{2}\right.$ e $\left.\mathrm{H}_{2} \mathrm{O}\right)$ da reação, se é utilizada uma fonte de média ou baixa potência. Portanto, para evitar a extinção do plasma, Thompson et al. ${ }^{90,91}$ empregaram níveis relativamente altos de potência $(2,7-5,0 \mathrm{~kW})$. Nesta ótica, sistemas de fluxo são preferidos aos de batelada, por produzirem, os primeiros, um fluxo constante destes subprodutos, o que permite a estabilização contínua do fundo, antes e depois da introdução do analito ${ }^{12}$.

Lichte e Skoberboe ${ }^{92}$, determinando As, foram pioneiros no acoplamento da geração de hidretos com MIP de argônio, à pressão atmosférica, com cavidade de Evenson $1 / 4$ do comprimento de onda. A principal dificuldade encontrada para este acoplamento é a instabilidade ou a incompatibilidade do MIP de pressão atmosférica com as quantidades abundantes de hidrogênio produzido durante a geração do hidreto, o que implicou no uso de uma armadilha crioscópica em nitrogênio líquido, para a separação dos hidretos liberados durante a reação ${ }^{12}$. Deste modo, a leitura faz-se em duas etapas: na primeira os hidretos gerados são capturados na armadilha, que deixa passar o hidrogênio. Na segunda, a armadilha é aquecida, os hidretos são liberados e transferidos para o plasma por um fluxo apropriado de argônio, livre do hidrogênio da etapa anterior. De qualquer modo, o processo é evidentemente mais trabalhoso, o que implica na sua baixa popularidade.

Embora ainda pouco conhecida, FANES é uma técnica muito sensível, que combina a vaporização eletrotérmica e a atomização com baixa pressão. $\mathrm{O}$ analito é vaporizado num forno de grafite contendo um catodo oco no seu interior, usando-se um programa de temperatura otimizado e baixa pressão $(1000-3000 \mathrm{~Pa})$. A excitação dos átomos é obtida pela aplicação de uma corrente elétrica variável, a qual gera uma descarga incandescente no catodo oco ${ }^{93}$. A combinação da geração de hidretos com uma fonte FANES, envolvendo o enriquecimento in situ dos analitos no forno de grafite, previamente tratado com Ir, foi usada como uma técnica de pré-concentração para a determinação simultânea de $\mathrm{As}, \mathrm{Bi}, \mathrm{Sb}$, Se e Te em amostras ambientais. A acuracidade da metodologia foi validada com amostras de referência certificadas ${ }^{94}$.

\section{Espectrometria de massas com plasma indutivamente acoplado}

A introdução direta de hidretos gerados em equipamentos ICPMS sofre das mesmas restrições discutidas acima para ICP-OES. Assim, para se aproveitar da capacidade máxima de detecção do equipamento, e pelo fato de os equipamentos modernos já disporem de acessórios adequados, vários autores têm investido na pré-concentração 
multielementar dos hidretos voláteis em um forno de grafite, com sua determinação subseqüente por ICP-MS (HG-ETV-ICP-MS). Esta metodologia oferece várias vantagens, incluindo a pré-concentração dos analitos e eliminação do hidrogênio, melhorando, assim, a estabilidade do plasma. Nos primeiros estudos, os hidretos de As, Bi e Te eram coletados no forno de grafite tratado com Pd, e subseqüentemente vaporizados simultaneamente e determinados por ICP-MS. A exatidão deste procedimento pode ser comprovada por Matusiewicz e Sturgeon ${ }^{95}$, inclusive na análise de um material de referência certificado. Também Sturgeon e Gregoire ${ }^{96}$ retiveram os hidretos voláteis de $\mathrm{As}, \mathrm{Bi}, \mathrm{Sb}, \mathrm{Se}$ e $\mathrm{Sn}$ em um tubo de grafite com sua superfície interna recoberta por um filme fino de paládio, previamente aí formado pela redução do $\mathrm{PdCl}_{2}$, a $400{ }^{\circ} \mathrm{C}$, utilizando um sistema ETV-ICP-MS comercial. As eficiências de geração e transporte foram, em média, melhores que $75 \%$, com a exceção do Se. O parâmetro crítico mostrou ser a eficiência de transporte do analito para o ICP, que é altamente dependente da nucleação na fase gasosa, que se dá mesmo em distâncias pequenas. Por esta razão, percebeu-se que o uso de Ir, como modificador permanente, não é aconselhável, por impedir a transferência eficaz do analito para fora do forno de grafite, antes da detecção. Nestas circunstâncias, foi mais conveniente preparar, previamente a cada medida, um novo depósito de Pd reduzido. Determinações multielementares de As, Bi e Se foram possíveis usando-se uma mesma condição experimental, enquanto que as determinações para Sb e Se foram realizadas em um experimento separado, devido ao diferente pH ótimo para a geração dos hidretos. Os limites de detecção obtidos no modo multielementar ficaram limitados pelo nível do branco, com exceção do Se, e foram dez vezes melhores do que aqueles alcançados usando-se a detecção direta por AAS ou a introdução direta dos hidretos no ICP-MS. A aplicação de sistema de pré-concentração in situ provavelmente oferecerá uma melhora adicional no desempenho analítico desta metodologia ${ }^{95}$.

\section{Mecanismo de atomização}

As altas temperaturas de plasmas e chamas podem permitir a admissão de um mecanismo de atomização via decomposição térmica. Entretanto, este mecanismo não resiste a uma análise termodinâmica quando da atomização em tubos de quartzo, dadas suas temperaturas relativamente baixas $\left(<1000{ }^{\circ} \mathrm{C}\right)$ e os valores do $\Delta \mathrm{G}$ de formação dos hidretos em questão. De acordo com cálculos termodinâmicos, as únicas espécies gasosas que podem ser esperadas em temperaturas abaixo de $1000{ }^{\circ} \mathrm{C}$ são moléculas dímeras e não átomos ${ }^{14,53}$. Assim, acreditase que a atomização dos hidretos gasosos no tubo de quartzo aquecido é mediada por átomos de hidrogênio livres, ao invés da decomposição térmica. Sabe-se, por outro lado, que não se obtém sinal de atomização do As quando a arsina é introduzida em uma célula de quartzo aquecida, em uma atmosfera contendo apenas o gás inerte, isto é, na ausência de hidrogênio ${ }^{97}$. Embora o mecanismo de formação de radicais $\mathrm{H}$ não seja bem entendido, traços de oxigênio parecem desempenhar um papel importante na geração desses radicais, de acordo com as seguintes reações ${ }^{98}$ :

$\mathrm{H}+\mathrm{O}_{2} \leftrightharpoons \mathrm{OH}+\mathrm{O}$

$\mathrm{O}+\mathrm{H}_{2} \leftrightharpoons \mathrm{OH}+\mathrm{H}$

$\mathrm{OH}+\mathrm{H}_{2} \leftrightharpoons \mathrm{H}_{2} \mathrm{O}+\mathrm{H}$

O mecanismo de atomização do hidreto ocorre via interação dos hidretos com radicais $\mathrm{H}$. Para o Se, por exemplo, duas reações consecutivas devem ocorrer:

$\mathrm{SeH}_{2}+\mathrm{H} \rightarrow \mathrm{SeH}+\mathrm{H}_{2}$

$\mathrm{SeH}+\mathrm{H} \rightarrow \mathrm{Se}+\mathrm{H}_{2}$
Reações semelhantes ocorrem para o hidreto de As e, provavelmente, para outros hidretos também ${ }^{53}$. Contudo, com base nas concentrações de equilíbrio dos radicais livres e nas temperaturas existentes no tubo de quartzo aquecido, conclui-se que a equação (4) não é provável, sendo que pode ocorrer a do tipo (5). Então, outros mecanismos têm sido propostos para atomização do $\mathrm{AsH}_{3}^{99}$ :

$2 \mathrm{AsH}_{3} \rightarrow 2 \mathrm{As}+3 \mathrm{H}_{2}$

$4 \mathrm{AsH}_{3}+3 \mathrm{O}_{2} \rightarrow 4 \mathrm{As}+6 \mathrm{H}_{2} \mathrm{O}$

catalisados pelos radicais $\mathrm{H}$ e $\mathrm{OH}$. $\mathrm{O}$ efeito positivo do $\mathrm{H}$ e $\mathrm{O}$ na atomização de elementos formadores de hidretos em um atomizador de quartzo aquecido eletricamente, foi confirmado na determinação de As, Se, Bi, Sb e Sn ${ }^{99-102}$. Já o mecanismo de atomização dos hidretos no tubo de grafite, encontra-se discutido por Dedina e colaboradores $^{14,53}$, Wang e colaboradores ${ }^{103}$ e Shaikl e colaboradores ${ }^{104}$. A volatilização pode se dar com o As na forma de $\mathrm{As}_{2}$, com posterior atomização do dímero na fase gasosa ${ }^{80}$. O fato da influência do hidrogênio na atomização do hidreto de As ser menor em temperaturas maiores no forno de grafite sugere que o mecanismo de atomização por decomposição térmica desempenha a principal função ${ }^{105}$. No caso da pré-concentração in situ, o mecanismo de aprisionamento foi investigado por Sturgeon ${ }^{106}$, que concluiu serem aí os processos de atomização semelhantes aos que se observam para soluções aquosas destes analitos diretamente adicionadas ao forno.

\section{Interferências}

Conforme já apontado, a geração química de vapor, por implicar na separação do analito da matriz, tende a ser um método de introdução de amostras que minimiza interferências. Entretanto, elas são encontradas e estão relacionadas às diferentes fases do processo, ou seja, à reação de geração e liberação do vapor da solução (interferências de fase condensada), ao transporte do vapor (interferências na fase gasosa), e ao processo de atomização/leitura (interferências na fase gasosa e interferências espectrais). Na seqüência, serão consideradas as interferências relativas à geração de hidretos, utilizandose $\mathrm{NaBH}_{4}$ como redutor.

\section{Interferências na fase condensada}

São as que ocorrem no frasco de reação, dentro da solução ou na interface solução/fase gasosa. Envolvem os processos de formação do hidreto e/ou de sua liberação da solução, neste caso devido a variações na velocidade de saída do hidreto (interferência na cinética de liberação). Podem envolver, ainda, a não disponibilização do hidreto pela presença de um concomitante que o retenha ou modifique. Como são relativas ao processo de geração e liberação do vapor formado, são independentes do método posterior de detecção e, assim, as discussões que se seguem são válidas para sistemas HG-AAS, HG-ICP-OES, HG-AFS, etc.

Em relação às interferências na cinética de redução sabe-se, por exemplo, que As, Sb, Se e Te podem existir, em solução, em dois estados de oxidação: As(III)/As(V); $\mathrm{Sb}$ (III)/Sb(V); $\mathrm{Se}(\mathrm{IV}) / \mathrm{Se}(\mathrm{VI})$ e $\mathrm{Te}(\mathrm{IV}) / \mathrm{Te}(\mathrm{VI})$ e que estados de oxidação mais altos apresentam velocidade de redução mais lenta. No caso do grupo 15 da tabela periódica (As, $\mathrm{Sb}$ e Bi), o estado +5 leva a sinais menores que o estado +3. Quanto ao grupo 16 (Se e Te), o estado +6 não leva a sinal perceptível, sendo imperativo proceder à redução prévia ao estado de oxidação +4 , antes da determinação $0^{14,41}$. Mesmo para o grupo 15 (As e $\mathrm{Sb}$ ) a redução prévia tem sido utilizada, sendo os pré-redutores mais comuns o $\mathrm{KI}^{107-111}$, o $\mathrm{NaI}^{112}$, o $\mathrm{KBr}^{29}$ e misturas de $\mathrm{KI}$ e ácido ascórbico ${ }^{113-115} ; \mathrm{SnCl}_{2}{ }^{116}$ ou aquecimento da amostra em $\mathrm{HCl} 4$ a 5 $\mathrm{mol} / \mathrm{L}^{117-120}$ também têm sido sugeridos. De modo similar, o Te(VI) 
pode ser pré-reduzido a Te(IV) por ebulição da amostra em $\mathrm{HCl} 2$ a $6 \mathrm{~mol} / \mathrm{L}$, por 10 a $20 \mathrm{~min}^{35,121}$. Por outro lado, estas propriedades distintas dos diferentes estados de oxidação são úteis na especiação química, permitindo, por exemplo, determinações seletivas de As(III) e $\mathrm{As}(\mathrm{V})^{108}, \mathrm{Sb}(\mathrm{III})$ e $\mathrm{Sb}(\mathrm{V})^{122}$ e $\mathrm{Se}(\mathrm{IV})$ e $\mathrm{Se}(\mathrm{VI})^{118-123}$, por diferença.

Além da possibilidade de diferentes números de oxidação, os elementos formadores de hidretos podem existir ligados a diferentes radicais orgânicos, seja em amostras ambientais ou biológicas. Como estas diferentes formas podem apresentar distintas cinéticas de redução, faz-se necessário liberar o analito completamente destes radicais para a determinação do seu conteúdo total. Esta liberação é feita durante a digestão da amostra, especialmente por procedimentos que utilizam aquecimento assistido por microondas ${ }^{85}$. De modo análogo, estes comportamentos distintos podem ser utilizados para as determinações de diferentes formas dos elementos formadores de hidretos em amostras biológicas e ambientais. O procedimento envolve geração de hidretos, a partir dos derivados orgânicos e inorgânicos do elemento em questão, com o $\mathrm{NaBH}_{4}$, e coleta destes hidretos em armadilha de nitrogênio líquido. Subseqüentemente, as várias espécies de hidretos são separadas por volatilização seletiva e alcançam o atomizador em tempos distintos, dando sinais sucessivos de absorvância, cada qual relativo a uma espécie. Deste modo, é possível a especiação de $\mathrm{As}^{124}, \mathrm{Ge}^{125}, \mathrm{~Pb}^{126}$ e $\mathrm{Sn}^{127}$ por AAS. Outra possibilidade é controlar a redução pelo ajuste do $\mathrm{pH}$ do meio, quando diferentes espécies são reduzidas em valores específicos de $\mathrm{pH}^{128}$.

Interferências cinéticas também se relacionam à liberação do hidreto formado, do seio da solução para a fase gasosa. Por exemplo, em sistemas em batelada, sinais distintos são obtidos para diferentes volumes de solução no frasco de reação, com maiores volumes apresentando sinais relativamente mais largos e de menor altura. Outra possibilidade é a formação de espuma em determinados tipos de amostra, o que também concorre para a mudança na cinética de liberação dos hidretos em solução e, conseqüentemente, na forma do sinal de absorvância ${ }^{53}$. Este tipo de interferência pode ser contornado pelo uso de anti-espumantes, sejam eles álcoois de cadeia carbônica longa ou substâncias à base de silicone.

A interferência na disponibilização dos hidretos ocorre quando algum concomitante impede a reação de formação do hidreto do analito, ou leva à sua transformação, imediatamente após a sua formação, a uma forma não transportável para a fase gasosa. Neste sentido, Smith ${ }^{129}$ investigou a influência de 48 elementos na determinação de As, Bi, Ge, Sb, Se, Sn e Te por HGAAS, observando que muitos destes elementos que interferem formam um precipitado após a adição do redutor. Ele sugeriu que a interferência se dá pela redução preferencial do íon metálico interferente, presente na solução, para a forma elementar coloidal, causando a co-precipitação do analito ou a adsorção do hidreto volátil formado e sua decomposição catalítica. Metais alcalinos e alcalinos terrosos não interferem, ao contrário de íons que podem ser facilmente reduzidos pelo $\mathrm{NaBH}_{4}$, tais como $\mathrm{Co}(\mathrm{II}), \mathrm{Ni}(\mathrm{II})$ e $\mathrm{Cu}(\mathrm{II})$. O arseneto de níquel (insolúvel), ou substâncias similares, também pode ser formado, em uma reação secundária ${ }^{130}$. O efeito catalítico mencionado pode ser devido ao próprio íon metálico, às partículas metálicas finamente divididas, formadas pela sua redução pelo $\mathrm{NaBH}_{4}$, ou pela formação de boratos metálicos ${ }^{131}$

A influência de ácidos inorgânicos também tem sido sistematicamente estudada ${ }^{51,132-134}$, sendo reconhecido o efeito supressor do $\mathrm{HNO}_{3}$ e do $\mathrm{H}_{2} \mathrm{SO}_{4}$, a partir de determinadas concentrações. Estas interferências são mais pronunciadas em tubos de atomização de quartzo com extremidades fechadas que em tubos com extremidades abertas $^{62,132}$. Quantidades excessivas de $\mathrm{HCl}$, podem, também, levar à uma diminuição do sinal analítico, sendo que o $\mathrm{HF}$ pode também ser interferente ${ }^{24}$.
Constituintes orgânicos da matriz são interferentes potenciais ${ }^{135,136}$ : ácidos húmicos ${ }^{137}$ e substâncias orgânicas não específicas, dissolvidas em águas ${ }^{53}$, interferem na liberação do hidreto de selênio, comportamento também de certos agentes quelantes ${ }^{14,24}$.

\section{Interferências na fase gasosa}

Estas interferências podem ocorrer no volume morto do frasco de reação, na linha de transporte ou no atomizador, e se manifestam imediatamente (se observada simultaneamente com a geração do interferente) ou por um efeito de memória (se persistir após cessar a geração do interferente). Dois grupos de interferências podem ser distinguidos: as "interferências de transporte", que ocorrem ao longo do transporte do hidreto, já liberado da solução, para o atomizador, causando atraso (interferência na cinética de transporte) e/ou perdas (interferência na eficiência de transporte); no segundo grupo estão as interferências que se dão no processo de atomização, e relacionam-se ao mecanismo de atomização. Neste grupo estão as chamadas interferências mútuas dos elementos formadores de hidretos: $\mathrm{O}$ excesso de um outro elemento formador de hidreto termina por levar à queda do sinal analítico. Este tipo de interferência pode ser interpretado de dois modos: o interferente faz cair a concentração dos radicais $\mathrm{H}$ no interior do atomizador, ou acelera o decaimento dos átomos livres do analito no atomizador, via reações analito-interferente, que podem resultar na formação de moléculas diatômicas estáveis, tais como $\mathrm{AsSb}^{138-140}$.

\section{Interferências espectrais}

$\mathrm{Na}$ espectrometria atômica, a interferência espectral ocorre quando o detector interpreta um sinal, que não do analito, como se dele fosse. Podem ser, primeiramente, ocasionadas pela presença de espécies atômicas que absorvam ou emitam radiação no mesmo comprimento de onda que o analito (sobreposição de linhas atômicas). Este tipo de interferência é muito raro na absorção e fluorescência atômicas em geral, e os casos existentes são bem conhecidos e não se aplicam à geração de hidretos. No caso da emissão atômica, pela riqueza em linhas do espectro gerado, este tipo de interferência é mais comum mas, como na geração química de vapor a matriz é deixada para traz, no frasco de reação, o problema é contornado. Uma possibilidade mais freqüente na absorção atômica é a presença de espécies moleculares ou partículas (presentes pela atomização incompleta da matriz) no caminho ótico, que também atenuem a radiação primária. No caso da geração de hidretos, essas interferências são usualmente insignificantes, devido à separação do analito da matriz. Na atomização em chama de difusão, absorções de fundo acontecem devido a variações na transparência da chama, que podem ocorrer quando o hidreto é purgado para o atomizador. Um fundo estruturado, devido ao oxigênio molecular, mostrou ser responsável pela absorção de fundo presente na linha do selênio $(196,0 \mathrm{~nm})^{14,53}$. Radiação de fundo é também observada na determinação de Se, se grandes quantidades de As, Sb e Sn estiverem presentes na amostra. Hidretos destes elementos são concomitantemente gerados e apresentam bandas moleculares na linha analítica do Se. Este tipo de interferência é pronunciado em atomizadores do tipo tubo T externamente aquecido ${ }^{56,106}$. Mesmo assim, a correção de fundo é considerada desnecessária na atomização em tubos de quartzo aquecidos externamente ${ }^{52,141,142}$, na coleta in situ no forno de grafite e na atomização direta no forno de grafite ${ }^{73,143}$. No caso da emissão ótica, dada a maior temperatura do plasma, tais moléculas não ocorrem; entretanto, um fundo estável deve ser garantido, em função do efeito de co-transporte de hidrogênio.

\section{Controle e eliminação de interferências}

Muitos métodos têm sido desenvolvidos para eliminar ou minimizar as interferências relatadas, em especial as interferências em fase condensada, as mais importantes. Um dos mais simples faz 
uso do aumento da acidez da solução e/ou do controle da concentração do reagente redutor ${ }^{142,144-149}$. Welz e Schubert-Jacobs ${ }^{145}$, por exemplo, observaram que, elevando a concentração do $\mathrm{HCl}$ de 0,5 para $5 \mathrm{~mol} / \mathrm{L}$, podem ser toleradas maiores razões interferente/analito na determinação de As e Se, na presença de $\mathrm{Ni}, \mathrm{Co}$ e $\mathrm{Cu}$, e que a diminuição da concentração do redutor de 3 para $0,5 \% \mathrm{~m} / \mathrm{v}$ também permite maiores razões interferente/analito, com exceção para interferência do $\mathrm{Cu}$ no sinal do $\mathrm{Se}$, onde o efeito é menos pronunciado em concentrações maiores do redutor.

Além do controle da acidez e da concentração do redutor, inúmeros procedimentos de separação do interferente têm sido propostos, tanto fora de linha ${ }^{52,147-149}$, como em linha ${ }^{150}$. Praticamente todos os métodos de separação estão contemplados: precipitação ${ }^{151}$, troca iônica ${ }^{152}$, co-precipitação ${ }^{153}$, eletrodeposição ${ }^{154,155}$, extração por solvente ${ }^{156}$, etc.

Mais atraente do que a separação do interferente parece ser a neutralização da ação interferente pela adição de um agente mascarante. Vários destes agentes foram sugeridos, e estão mostrados, junto com algumas figuras de mérito, na Tabela 1. Deve-se destacar os agentes quelantes que se mostram eficientes em meio bastante ácido, evitando o uso de soluções tampão, que causam, com matrizes complexas, o desconforto de reações paralelas indesejáveis.

Além da adição de agentes quelantes, outro tipo de reagente pode ser adicionado à solução: são as espécies que agem controlando o potencial do meio, permitindo a formação do hidreto, mas não deixando que o potencial de redução do interferente seja alcançado. Ou seja, são espécies cujo par redox não interfere, e com potencial de redução situado entre aquele relativo à redução do analito a hidreto e aquele da redução do íon interferente à sua forma metálica. Um destes "controladores de potencial" é o Fe(III), efetivo para controlar a interferência do Ni e Co na determinação do Te ${ }^{157}$ ou As e $\mathrm{Se}^{142,144}$

Takase et al. ${ }^{158}$ investigaram a interferência dos metais de transição ( $\mathrm{Co}, \mathrm{Cu}, \mathrm{Fe}$ e Ni) na determinação de As, Bi, Sb e Se por HGAAS, utilizando sistemas FIA e batelada. Este estudo mostrou que não é possível generalizar a assertiva de que sistemas em fluxo levam sempre aos maiores limites de tolerância. Outro aspecto importante observado quanto à interferência do $\mathrm{Cu}$ e do $\mathrm{Ni}$ refere-se à potencialização do efeito interferente de um deles pela presença do outro, ainda que este esteja em concentração abaixo do limite de tolerância. Trata-se de um tipo de efeito sinérgico que põe em cheque o mecanismo de interferência via redução usualmente aceito. Porém, foi observado que, embora a interferência causada pela presença simultânea destes dois elementos não pudesse ser contornada por um único agente quelante, uma mistura de ácido picolínico e L-cisteína pode minimizá-la ${ }^{159,160}$. Entretanto, embora tenha havido sucesso na minimização ou eliminação de interferências pelos métodos discutidos, a adição do analito ainda é essencial em muitos casos ${ }^{161,162}$.

Tabela 1. Adição de agentes quelantes na determinação de As, Bi, Sb, Se, Sn e Te

\begin{tabular}{|c|c|c|c|c|c|c|}
\hline Analito & Amostra & $\begin{array}{l}\text { Concentração }\left(\mu \mathrm{g} \mathrm{mL}^{-1}\right) \text { ou } \\
\text { razão (x vezes) de interferência } \\
\text { tolerada }\end{array}$ & Quelante & Meio & Sistema & Ref. \\
\hline As & biológica & Fe e Cu: $100 ; \mathrm{Ni}: 2$ & EDTA & $\mathrm{HCl} 1 \mathrm{~mol} / \mathrm{L}$ & FIA & 290 \\
\hline As & biológica & Co, Cu e Ni: 10000x & $\mathrm{KI}+$ hidroxilamina & $\mathrm{HCl} 6 \mathrm{~mol} / \mathrm{L}$ & FIA & 291 \\
\hline As & metais & Ni e Cu: 1000x; Pt e Pd: 100x & $\begin{array}{l}\text { 1,10-fenantrolina e/ou } \\
\text { tiosemicarbazida }\end{array}$ & $\mathrm{HCl} 0,5 \mathrm{M}$ & batelada & 292 \\
\hline As e $\mathrm{Sb}$ & cobre e aços & $\begin{array}{l}\mathrm{Cu}: 1000(\mathrm{As}) \text { e } 500(\mathrm{Sb}) \\
\mathrm{Ni}: 200(\mathrm{As}) \text { e } 250(\mathrm{Sb})\end{array}$ & $\mathrm{L}$ - cisteína & $\begin{array}{l}\mathrm{HCl} 1 \mathrm{~mol} / \mathrm{L}(\mathrm{As}) \\
\text { e } 0,1 \mathrm{~mol} / \mathrm{L}(\mathrm{Sb})\end{array}$ & FIA & $\begin{array}{l}293 \\
294\end{array}$ \\
\hline $\mathrm{Bi}$ & material geológico & $\mathrm{Cu}: 1000 \mathrm{x}$ & Tiouréia & $\mathrm{HCl} 1 \mathrm{~mol} / \mathrm{L}$ & FIA & 295 \\
\hline $\mathrm{Bi}$ & metais & Ni e Co: 5000; Ag: 200; Cu: 1000 & Tiouréia + KI & $\mathrm{HCl} 1 \mathrm{~mol} / \mathrm{L}$ & FIA & 209 \\
\hline $\mathrm{Bi}$ & ligas de $\mathrm{Cu}$ & $\mathrm{Cu}: 1000$ & Tiouréia & $\mathrm{HCl} 20 \% \mathrm{v} / \mathrm{v}$ & batelada & 296 \\
\hline $\mathrm{Bi}$ & liga de $\mathrm{Ni}$ & Ni: ? & EDTA & $\mathrm{pH}=4,2$ & batelada & 297 \\
\hline $\mathrm{Bi}$ & ligas de $\mathrm{Cu}$ & $\mathrm{Cu}: 2$ & Tiosemicarbazida & $\mathrm{HCl} 0,2 \mathrm{~mol} / \mathrm{L}$ & batelada & 298 \\
\hline $\mathrm{Bi}$ & ligas de $\mathrm{Cu}$ & $\mathrm{Cu}: 5 \times 10^{4}$ & DDTP & $\mathrm{HCl} 10 \% \mathrm{v} / \mathrm{v}$ & batelada & 299 \\
\hline $\mathrm{Bi}$ & ligas de $\mathrm{Ni}$ e $\mathrm{Cu}$ & $\mathrm{Ni}: 6 \times 10^{4} ; \mathrm{Cu}: 1 \times 10^{4}$ & TAC & $\mathrm{HCl} 10 \% \mathrm{v} / \mathrm{v}$ & batelada & 300 \\
\hline $\mathrm{Bi}$ e $\mathrm{Sb}$ & ambiental & Ni: $10000 x$ & 1,10-fenantrolina & $\begin{array}{l}\mathrm{H}_{2} \mathrm{SO}_{4} 1 \mathrm{~mol} / \mathrm{L}(\mathrm{Bi}) \\
\text { e } 0,5 \mathrm{~mol} / \mathrm{L}(\mathrm{Sb})\end{array}$ & batelada & 301 \\
\hline $\mathrm{Sb}$ & ligas de $\mathrm{Cu}$ e água & $\mathrm{Cu}$ e Ni: $1000 x$ & Tiouréia & $\mathrm{HCl} 1 \mathrm{~mol} / \mathrm{L}$ & FIA & 295 \\
\hline $\mathrm{Sb}$ & ligas de $\mathrm{Ni}$ & Ni: 10000x; Cu: 200x & Ácido picolínico & $\mathrm{HCl} 1 \% \mathrm{v} / \mathrm{v}$ & batelada & 302 \\
\hline $\mathrm{Se}$ & ligas & Ni e Co: 8000 & EDTA/DTPA & $\mathrm{pH}=12-13$ & FIA & 303 \\
\hline $\mathrm{Se}$ & minério de $\mathrm{Zn}$ & $\mathrm{Cu}: 1500$ & Tiouréia & $\mathrm{HCl} 2 \mathrm{~mol} / \mathrm{L}$ & batelada & 157 \\
\hline $\mathrm{Se}$ & amostra de $\mathrm{Ni}$ & Ni: 1600 & Ácido cítrico & $\mathrm{HCl} 0,6 \mathrm{~mol} / \mathrm{L}$ & batelada & 304 \\
\hline $\mathrm{Sn}$ & ligas & $\mathrm{Ni}, \mathrm{Cu}$ e $\mathrm{Au}: 20$ & $\mathrm{KCN}$ & $\mathrm{HCl} 1 \% \mathrm{v} / \mathrm{v}$ & FIA & 305 \\
\hline Te e As & ligas de $\mathrm{Ni}$ e $\mathrm{Cu}$ & Ni, Co e Cu: 5000 & DTPA & $\mathrm{pH}=12$ & HG-ICPOES & 306 \\
\hline
\end{tabular}




\section{Aplicações}

Existem, na literatura, inúmeras aplicações da técnica de geração de hidretos com detecção por espectrometria atômica, em uma ampla variedade de amostras: alimentos $(\mathrm{As})^{163-166}$; água $(\mathrm{As})^{6,167-172},(\mathrm{~Pb})^{173}$, $(\mathrm{Sn})^{174},(\mathrm{Sb})^{175-177},(\mathrm{Se})^{178-180},(\mathrm{Tl})^{181},(\mathrm{As} \text { e Se})^{182},\left(\mathrm{As}, \mathrm{Se}\right.$ e Sb) ${ }^{183},(\mathrm{As}$, $\mathrm{Se}, \mathrm{Sb}$ e Ge$)^{184}$; água e solo $(\mathrm{Pb})^{185}$, amostras ambientais $(\mathrm{As})^{186},(\mathrm{Cd})^{187}$, $(\mathrm{Sb})^{188,189},(\mathrm{Sn})^{190}$; amostras biológicas $(\mathrm{Se})^{7}$, (As e $\left.\mathrm{Bi}\right)^{191}$; amostras biológicas e ambientais $(\mathrm{As})^{192},(\mathrm{Cd})^{193}$, (As e Se $)^{194}$; amostras clínicas: cabelo $(\mathrm{Se})^{195},(\mathrm{Sb})^{196}$, urina $(\mathrm{As})^{197-201},(\mathrm{Bi})^{202},(\mathrm{Se})^{203,205}$; bebidas: vinho $(\mathrm{Sb})^{206}$, vinho e cerveja $(\mathrm{As})^{207}$; metais e ligas metálicas $(\mathrm{As})^{208}$, $(\mathrm{Bi})^{209}$, (As, Bi, Sb, Se e Te $)^{210}$; fumo (As) $)^{211}$; catalisador $(\mathrm{As})^{212}$; óleo lubrificante $(\mathrm{Sn})^{213}$; plantas $(\mathrm{Sb})^{214}$; solo $(\mathrm{As})^{215}(\mathrm{Se})^{216}$; sedimento $(\mathrm{As})^{217,218}(\mathrm{As}, \mathrm{Bi}, \mathrm{Sb} \text { e Sn })^{219}$; amostras geológicas (Bi, Sb, Se e Te $)^{220}$; suplemento nutricional $(\mathrm{Se})^{221}$; xampu $(\mathrm{Se})^{222}$, etc.

\section{Extensões da técnica}

Ainda que, nesta revisão, tenha sido dada ênfase aos elementos formadores de hidretos covalentes, é importante registrar o aparecimento recente, na literatura de alguns artigos estendendo a técnica de geração química de vapor pelo tetraidroborato de sódio a metais, como $\mathrm{Ag}, \mathrm{Au}$, $\mathrm{Cd}, \mathrm{Cu}, \mathrm{Ni}, \mathrm{Pd}, \mathrm{Rh}$ e $\mathrm{Zn}^{22,223}$.

\section{A GERAÇÃO QUÍMICA DE SUBSTÂNCIAS VOLÁTEIS ATRAVÉS DE REAÇÕES DE ALQUILAÇÃO E ARILAÇÃO}

\section{Reagentes de Grignard}

Reagentes de Grignard, $\mathrm{RMgX}$, onde R é um radical alquila e X um halogênio, têm sido largamente utilizados em reações de alquilação na química orgânica. No caso de interesse aqui, a alquilação dá-se à espécie que se deseja tornar volátil. Assim, por exemplo, compostos de Sn, como a família que vai do mono ao tributilestanho, podem reagir com o brometo de pentilmagnésio e os derivados pentilados formados podem ser determinados por GC-AAS. Os derivados alquilados, tal como encontrados originalmente na amostra, podem possuir características cromatográficas longe da ideal e, especialmente quando se utiliza a cromatografia em fase gasosa, estas espécies químicas devem ser convertidas para espécies voláteis e termicamente mais estáveis. Para este propósito, a derivatização do analito com o reagente de Grignard deve formar uma espécie química que atenda aos requisitos da cromatografia gasosa. Deve-se observar que é possível a formação de compostos voláteis de Sn utilizando o próprio tetrahidroborato de sódio; entretanto, nem todos os organoderivados de Sn reagem com esta substância, o que limita o uso deste reagente em estudos de especiação, inclusive para outros elementos.

Assim, na análise de sangue, Emteborg et al. ${ }^{224}$ extraíram as espécies de mercúrio com tolueno, na forma de complexos de dietilditiocarbamato, posteriormente alquilados com o cloreto de butilmagnésio e introduzidos em um sistema GC-MIP-OES. Para a especiação do mercúrio em águas naturais e em águas naturais ricas em ácidos húmicos, foi introduzida uma etapa de pré-concentração com uma resina impregnada com dietilditiocarbamato ${ }^{225,226}$. Uma coluna capilar, colocada em série, permitiu aumentar o volume de amostra introduzida, levando à especiação de mercúrio em águas naturais ${ }^{227}$. Já a amalgamação e a micro-extração em fase sólida foram utilizadas por Frech et al. ${ }^{228}$ na especiação do mercúrio em amostras ambientais utilizando GCMIP-OES. A derivatização do $\mathrm{Pb}$ com o cloreto de butilmagnésio, com detecção por AAS, permitiu sua especiação em amostras ambientais. O limite de detecção obtido foi $7 \mu \mathrm{g} \mathrm{L}^{-1}$, para um volume de amostra de $100 \mathrm{~mL}^{229}$. Já Lobinski e Adams ${ }^{230}$, para amostras de águas naturais e neves polares, utilizaram um reagente de propilação (cloreto de propilmagnésio) e detecção por GC-OES. O limite de detecção foi de $0,1 \mathrm{ng} \mathrm{L}^{-1}$, expresso como $\mathrm{Pb}$. Posteriormente, Adams et al. ${ }^{231}$ utilizaram o sistema GC-ICP-MS na detecção de substâncias organoplúmbicas em amostras ambientais, usando o mesmo reagente de propilação. Os limites de detecção absolutos foram de $10 \mathrm{fg}$ (trimetilchumbo) e $16 \mathrm{fg}$ (dietilchumbo), tendo sido o método validado com uma amostra de referência certificada.

Em função de sua alta toxidez, a especiação de substâncias organoestânicas tem sido investigada por diversos pesquisadores. Deste modo, Zhang et al. ${ }^{232}$ utilizaram o brometo de etilmagnésio para a derivatização de substâncias organoestânicas, seguida da extração com solvente orgânico e detecção por GC-AAS. O limite de

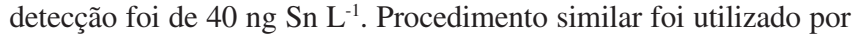
Wong $^{233}$. Stäb et al. ${ }^{234}$ especiaram organoestânicos em tecidos biológicos com detecção por GC-MS mas, neste caso, derivatizando-os com o iodeto de metilmagnésio, enquanto o brometo de pentilmagnésio foi utilizado por Fernandez ${ }^{235}$ na determinação de organoestânicos em sedimentos, após extração com tolueno-ácido acético, e determinação por GC-FPD pulsante.

Compostos voláteis de $\mathrm{Cd}$, Co e Ga podem também ser obtidos após derivatização com reagente de Grignard. Assim, Kamamaru e $\mathrm{TaO}^{236}$ determinaram $\mathrm{Cd}$ em amostras ambientais utilizando a derivatização pelo brometo de etilmagnésio, vaporização eletrotérmica e detecção por ICP-OES. (LD = $11 \mathrm{pg}$ ). O mesmo reagente foi investigado na determinação de cobalto ${ }^{237}$ e de gálio ${ }^{238}$.

\section{Tetraetilborato de sódio}

O tetraetilborato de sódio tem sido amplamente empregado para formação de etilderivados voláteis daqueles elementos que normalmente são determinados por geração de hidretos. Sua principal vantagem é realizar a reação de alquilação em fase aquosa, contrariamente ao reagente de Grignard, que se decompõe em água. Assim, Sanz-Medel et al. ${ }^{239}$ empregaram-no para a determinação de $\mathrm{Bi}(\mathrm{III})$ por AAS, usando um sistema de injeção em fluxo, obtendo um limite de detecção de $0,56 \mathrm{ng}$ $\mathrm{Bi}\left(0,8 \mu \mathrm{g} \mathrm{L}^{-1}\right)$, tendo sido o método aplicado em amostras de urina. $\mathrm{O}$ mesmo reagente foi empregado na determinação de cádmio por AFS em amostras ambientais ${ }^{240}$. Sanz-Medel et al. mostraram que a geração da espécie volátil de $\mathrm{Cd}$ (provavelmente $\mathrm{CdEt}_{2}$ ) podia ser aplicada na determinação de baixos níveis do elemento por ICP-OES ${ }^{241}$ ou ICP$\mathrm{MS}^{242}$. D'Ulivo e Chen ${ }^{242}$ compararam a determinação de cádmio por AFS e AAS, usando o mesmo reagente. O limite de detecção para AFS foi de $0,2 \mathrm{ng} \mathrm{mL}^{-1}$, enquanto que $1,0 \mathrm{ng} \mathrm{mL}^{-1}$ foi alcançado por AAS. O tetraetilborato de sódio foi também usado por Bloom ${ }^{243}$ na determinação de metilmercúrio por AFS, após coleta criogênica. O limite de detecção foi de 0,6 pg de metilmercúrio, que corresponde a uma concentração $0,003 \mathrm{ng} \mathrm{L}^{-1}$ para $200 \mathrm{~mL}$ de amostra. Semelhantemente, amostras de água de chuva ${ }^{244}$ e sedimento ${ }^{245}$ puderam ser especiadas usando as técnicas hifenadas GC-AFS e CG-ICP-MS ${ }^{246}$, enquanto Donard et $a l .{ }^{247}$ utilizaram a detecção por AAS em tubo de quartzo eletricamente aquecido. A determinação dos mesmos constituintes em amostras de peixe, foi realizada por Rapsomanikis et al. ${ }^{248}$ utilizando GC-AAS e por Adams et al. ${ }^{249}$ e Lobinski et al. ${ }^{250}$ usando a extração assistida por microondas e detecção por GC-MIP-OES. Sturgeon e Jimenez ${ }^{251}$ fizeram a especiação do mercúrio em amostras de tecido biológico usando GCFAPES, com limite de detecção absoluto de 1 e 7 pg para mercúrio e metilmercúrio, respectivamente. $\mathrm{O}$ método foi validado pela análise de amostras de referência certificadas.

Em relação ao chumbo, Sturgeon et al. ${ }^{252}$ propuseram sua etilação com este mesmo reagente e a coleta da espécie volátil no forno de grafite, para posterior detecção por AAS. A acuracidade foi testada pela análise de um material de referência certificado, alcançando-se um limite de detecção absoluto de 14 pg, semelhante quando da uti- 
lização de um sistema em fluxo ${ }^{253}$. GC-MIP-OES foi utilizado por Adams et al. tanto para a especiação de $\mathrm{Pb}^{254}$ como de $\mathrm{Sn}^{255-257}$, enquanto Allabashi et al. ${ }^{258}$ utilizaram a coleta da espécie volátil de Sn no forno de grafite, e detecção por AAS. Lobinski et al. ${ }^{259}$ descreveram um procedimento rápido para a determinação de mono-, di- e tributilestanho em sedimentos e materiais biológicos por GC-MIPOES, tendo sido o método também validado pela análise de amostra de referência certificada. Já Rapsomanikis et al. ${ }^{260,261}$ e Lobinski et $a l .{ }^{262}$ empregaram, na especiação de derivados orgânicos do estanho em amostras de sedimentos e materiais biológicos, a separação por GC, mas acoplada à detecção por AAS. Reações de derivatização com o tetraetilborato também podem ser empregadas em determinações simultâneas de espécies orgânicas de mercúrio, chumbo e estanho, seja por GC-MIP-OES ${ }^{263}$ (LD de 0,$15 ; 0,20$ e $0,60 \mathrm{ng} \mathrm{L}^{-1}$ ) ou por GC-ICP-MS ${ }^{264}$ (LD de 120, 100 e $50 \mathrm{fg}$ ).

\section{Tetrapropilborato de sódio}

Adams e Heisterkamp ${ }^{265}$ propuseram o tetrapropilborato de sódio como um novo reagente de derivatização para a especiação de organoplúmbicos, usando GC-MIP-OES. A derivatização foi feita em meio tamponado de ácido acético/acetato de sódio $(\mathrm{pH}=4,5)$ com extração posterior das espécies propiladas com hexano. Os limites de detecção variaram desde 77 até 102 fg e a acuracidade do procedimento foi confirmada pela análise de material de referência certificado. Jantzen et al. ${ }^{266}$ também utilizaram o tetrapropilborato de sódio na especiação dos derivados etilados de chumbo (di-, tri-, tetra), usando GC-AED obtendo um limite de detecção de 2 pg.

\section{Tetrafenilborato de sódio}

Wang et al. ${ }^{267}$ utilizaram o tetrafenilborato de sódio na determinação de metilmercúrio em águas naturais, com detecção por GCMS. A reação de derivatização em fase aquosa conduz à formação de uma espécie hidrofóbica, que é extraída com diclorometano. O limite de detecção foi de $1 \mathrm{ng} \mathrm{mL} \mathrm{m}^{-1}$, para uma amostra de $100 \mathrm{~mL}$ de água. Yang et al. ${ }^{268}$ propuseram um método para diferenciar o mercúrio do metil-mercúrio com o mesmo reagente de derivatização, utilizando extração com fluído supercrítico e detecção por AAS.

\section{Outras reações de alquilação}

Kumamaru et al. ${ }^{269}$ utilizaram o butil-lítio na determinação de zinco (II), formando o dibutil zinco, volátil, o qual foi subseqüentemente transportado a um ICP-OES, aplicando o método na determinação do analito em preparações farmacêuticas. Em outro procedimento, Okamoto ${ }^{270}$ propôs a metilação do antimônio pelo metil-lítio, em meio de éter dietílico, para formar o metilantimônio, com vaporização do analito a $650{ }^{\circ} \mathrm{C}$ e posterior determinação por ICP-MS. O limite de detecção, para o antimônio, foi estimado em $0,10 \mathrm{pg}$, que corresponde a uma concentração de $1,0 \mathrm{pg}$ $\mathrm{mL}^{-1}$, para um volume injetado de $100 \mu \mathrm{L}$. Já o tetrabutilamônio foi utilizado por Adams e Heisterkamp ${ }^{271}$ para a especiação de derivados oganoplúmbicos em amostras ambientais, por GC-MIP-OES.

\section{OUTROS MÉTODOS DE GERAÇÃO QUÍMICA DE VAPOR}

\section{Geração química de quelatos metálicos}

Rigin $^{272}$ propôs a determinação de metais pesados em amostras de águas naturais através da reação de complexação do analito com o bis(trifluoretil) ditiocarbamato de amônio, seguido da extração do complexo com tetracloreto de carbono e detecção por GC-AFS. Este método foi validado para $\mathrm{Cd}, \mathrm{Co}, \mathrm{Cr}, \mathrm{Cu}, \mathrm{Fe}, \mathrm{Ni}, \mathrm{Pb}$ e $\mathrm{Zn}$ em amostra de referência certificada. $\mathrm{O}$ mesmo autor usou a trifluoracetilacetona para complexar $\mathrm{Ga}, \mathrm{Fe}, \mathrm{Cr}, \mathrm{Al}$ e Be, em meio tamponado de ácido acético/ acetato de sódio, seguido da extração com benzeno e detecção por GG-AFS ${ }^{273}$. Herold et al. ${ }^{274}$ propuseram um método para determinação de Te, através da reação do analito com o brometo de (4-fluorfenil) magnésio, usando como GC-MS, com diluição isotópica.

\section{Geração de óxidos voláteis}

Óxidos voláteis podem ser gerados a partir do analito em solução. $\mathrm{O}$ uso do $\mathrm{Ce}(\mathrm{IV})$ como oxidante para produzir $\mathrm{RuO}_{4}$, a partir da solução de $\mathrm{Ru}(\mathrm{III})$, melhorou a sensibilidade de sua determinação por AAS por chama por um fator de 60 , devido ao aumento da volatilidade do analito na câmera de nebulização e consequiente melhoria na taxa de transporte ${ }^{275}$. Um método similar foi empregado para gerar $\mathrm{OsO}_{4}$ volátil, usando $\mathrm{K}_{2} \mathrm{Cr}_{2} \mathrm{O}_{7}$ como oxidante ${ }^{276}$.

\section{Geração química de cloretos e fluoretos voláteis}

Cloretos voláteis podem ser formados quando o analito reage com uma solução concentrada de ácido clorídrico, sendo carreados para o atomizador por um gás de purga. A aplicação deste procedimento na determinação de As(III) por AAS permitiu maior tolerância à interferência de metais de transição, tais como Ni(II), Co(II), $\mathrm{Cu}(\mathrm{II})$ e $\mathrm{Fe}(\mathrm{II} / \mathrm{III})$, em relação ao método clássico de geração de hidretos com o tetrahidroborato de sódio ${ }^{277}$. Guo e Guo ${ }^{278}$ também utilizaram o mesmo reagente na determinação de Ge por AFS e não observaram nenhuma interferência quando aplicaram o método na análise de amostras de referência certificadas de sedimento, solo, rocha e minérios de cobre e molibdênio. $\mathrm{O}$ ácido clorídrico foi ainda utilizado por Smichowski e Farias ${ }^{279}$ na determinação de Ge por ICP-OES e observaram que a geração do cloreto fornece um método mais preciso e acurado, com dramática supressão de interferências na fase líquida e a capacidade de gerar o $\mathrm{GeCl}_{4}$ em presença de $\mathrm{HNO}_{3}$. Alternativamente, o $\mathrm{CuCl}_{2}$ sólido, a $470{ }^{\circ} \mathrm{C}$, foi utilizado para a geração de $\mathrm{SiCl}_{4}$ na determinação do $\mathrm{Si}$ em índio de elevada pureza por GFAAS $^{280}$. Outra alternativa é a geração de $\mathrm{AsCl}_{3}$ pelo $\mathrm{NaCl}$, em sistema de batelada e meio sulfúrico, com detecção por AAS chama, aplicado com sucesso na determinação de As em inseticida líqui$\mathrm{do}^{281}$. Para a geração de fluoretos, pode-se utilizar a reação com o $\mathrm{XeF}_{4}$ em autoclave ${ }^{282}$, ou a reação com $\mathrm{NaF}$ em meio sulfúrico ${ }^{283-285}$. Entretanto, a reação em autoclave foi abandonada, provavelmente em virtude da dificuldade operacional do procedimento.

\section{Geração química de carbonilníquel volátil}

A geração química do derivado carbonilado de níquel, volátil, foi sugerida como um meio para a determinação de níquel por AAS e ICP-MS em amostras de águas naturais: o níquel reage com o $\mathrm{CO}$, formando o carbonil níquel, em temperatura e pressão próximas daquelas encontradas no ambiente ${ }^{286}$. Assim, Lee ${ }^{287}$ empregou este método para determinar níquel por AAS chama em amostras de água do mar. Já Cammann e Erber ${ }^{288}$ realizaram a pré-concentração em linha do níquel por vaporização do derivado carbonilado e coleta no forno de grafite, com detecção por AAS. O limite de detecção foi de $0,18 \mu \mathrm{g} \mathrm{L}^{-1}$, para uma alça de amostragem de $500 \mu \mathrm{L}$. Em enfoque semelhante, Park e Yim ${ }^{289}$ determinaram níquel em águas naturais por ICP-MS. A eficiência de transporte do analito por este método foi estimada ser, no mínimo, $50 \%$ superior àquela que utiliza a nebulização pneumática. A quantificação por diluição isotópica mostrou ser um método ultra-sensível e, especialmente, livre de interferências na análise de águas naturais ao nível do sub-ppb. 


\section{CONCLUSÕES}

Entre os procedimentos de introdução de amostras por geração química de vapor, em espectrometria atômica, a geração de hidretos covalentes pelo tetrahidroborato de sódio é o que se encontra mais estabelecido, fazendo parte da rotina analítica de inúmeros laboratórios, em processos de batelada ou fluxo, especialmente na determinação de As e Se. Para os outros elementos, onde suas vantagens são menos evidentes, ou somente por uma questão de hábito, sua utilização tem sido mais restrita. Entretanto, tem-se observado sua contínua extensão a novos elementos, incluindo metais de transição. Novos métodos de detecção ou a extensão a novas matrizes também têm preocupado os pesquisadores, neste caso buscando-se procedimentos simples de superação das interferências. É importante notar também a busca por atomizadores com desenhos ótimos, o que passa pela melhor compreensão dos mecanismos de atomização. Em relação aos outros reagentes que levam à formação de voláteis, eles têm merecido atenção, mas nenhum ameaça a primazia do tetrahidroborato de sódio. Porém, se o interesse pela especiação é considerado, este quadro muda, sendo o tetraetilborato de sódio o que encontra maior aplicação, inclusive permitindo procedimentos simples de especiação que, sem dúvida, deverão vir a ser os eleitos, quando este tipo de análise se tornar uma rotina.

\section{GLOSSÁRIO DE ACRÔNIMOS}

AAS

AFS

CVAAS

CVAFS

DDTC

ETAAS

ETV-ICP-MS

FANES

FAPES

FIA

GC-AAS

GC - AED

GC - AFS

$\mathrm{GC}-\mathrm{FPD}$

GC - MS

GF-AAS

HG-AAS

ICP-MS

ICP-OES

LD

MIP-OES
Espectrometria de absorção atômica

Espectrometria de fluorescência atômica

Espectrometria de absorção atômica pela técnica do vapor frio

Espectrometria de fluorescência atômica pela técnica do vapor frio

\section{Dietilditiocarbamato}

Espectrometria de absorção atômica com atomização eletrotérmica

Espectrometria de massa por plasma indutivaEspectrometria de emissão ótica com excitação não térmica

Espectrometria de emissão ótica com excitação por plasma e vaporização eletrotérmica

\section{Análise por injeção em fluxo}

Cromatografia em fase gasosa acoplada com espectrometria de absorção atômica

Cromatografia gasosa com detector de emissão atômica

Cromatografia em fase gasosa acoplada com espectrometria de fluorescência atômica

Cromatografia gasosa com detector fotométrico por chama

Espectrometria de massa acoplada com cromatografia gasosa

Espectrotrometria de absorção atômica no forno de grafite

Espectrometria de absorção atômica por geração de hidreto

Espectrometria de massa por plasma indutivamente acoplado

Espectrometria de emissão ótica por plasma indutivamente acoplado

Limite de detecção

Espectrometria de emissão ótica com plasma induzido por microondas mente acoplado com vaporização eletrotérmica

\section{REFERÊNCIAS}

1. Nakahara, T.; Spectrochim. Acta Rev. 1991, 14, 95.

2. Schickling, C.; Yang, J.; Broekaert, J. A. C.; J. Anal. At. Spectrom. 1996, 11,739 .

3. Ding, W. W.; Sturgeon, R. E.; J. Anal. At. Spectrom. 1996, 11, 225.

4. Ding, W. W.; Sturgeon, R. E.; J. Anal. At. Spectrom. 1996, 11, 421.

5. Ding, W. W.; Sturgeon, R. E.; Spectrochim. Acta, Part B 1996, 51, 1325.

6. Machado, L. F. R.; Jacintho, A. O.; Menegário, A. A. ; Zagatto, E. A. G.; Giné, M. F.; J. Anal. At. Spectrom. 1998, 13, 1343.

7. Machado, L. F. R.; Jacintho, A. O.; Giné, M. F.; Quim. Nova. 2000, 23, 30.

8. Hatch, W. R.; Ott, W. L.; Anal. Chem. 1968, 40, 2085.

9. Poluektov, N. S.; Vitkun, R. A.; Zh. Anal. Khim. 1963, 18, 33.

10. Poluektov, N. S.; Vitkun, R. A.; Zelyukova, Y. A.; Zh. Anal. Khim. 1964, 19, 937.

11. Holak, W.; Anal. Chem. 1969, 41, 1712.

12. Nakahara, T.; Prog. Anal. At. Spectrosc. 1983, 6, 163.

13. Chu, R. C.; Barron, G. P.; Baumgarner, P. A.; Anal. Chem. 1972, 44, 1476.

14. Dedina, J.; Tsalev, D. L.; Hydride Generation Atomic Absorption Spectrometry, John Wiley \& Sons: New York, 1995.

15. Braman, R. S.; Justen, L. L.; Foreback, C. C.; Anal. Chem. 1972, 44, 2195.

16. Tanaka, T.; Nakamura, Y.; Mizuike, A.; Ono, A.; Anal. Sci. 1996, 12, 77.

17. Wei, M. T.; Jiang, S-J.; J. Anal. At. Spectrom. 1999, 14, 1177.

18. Liao, Y.; Li, A.; J. Anal. At. Spectrom. 1993, 8, 633.

19. Sanz-Medel, A.; Valdés-Hevia y Temprano, M. C.; García, N. B.; Fernández de la Campa, M. R.; Anal. Chem. 1995, 67, 2216.

20. Garrido, M. L.; Muñoz-Olivas, R.; Cámara, C. J.; J. Anal. At. Spectrom. 1998, 13, 295

21. Garrido, M. L.; Muñoz-Olivas, R.; Cámara, C. J.; J. Anal. At. Spectrom. 1998, 13, 1145.

22. Luna, A. S.; Sturgeon, R. E.; Campos, R. C.; Anal. Chem. 2000, 72, 3523.

23. Luna, A. S.; Tese de Doutorado, Pontifícia Universidade Católica do Rio de Janeiro, Rio de Janeiro, Brasil, 2000.

24. Yan, X-P.; Ni, Z-M.; Anal. Chim. Acta 1994, 291, 89.

25. Lajunem, L. H. J.; Spectrochemical Analysis by Atomic Absorption and Emission, Royal Society of Chemistry: London, 1992.

26. Godden, R. G.; Thomerson, D. R.; Analyst 1980, 105, 1137.

27. Pollock, E. N.; West, S. J.; At. Absorption Newsl. 1972, 11, 104.

28. Welz, B.; Melcher, M.; At. Absorption Newsl. 1979, 18, 121.

29. Narasaki, H.; Ikeda, M.; Anal. Chem. 1984, 56, 2059.

30. Branch, C. H.; Hutchison, D.; Analyst 1985, 110, 163.

31. Sanzolone, R. F.; Chao, T. T.; Welsch, E. P.; Anal. Chim. Acta 1979, 108, 357.

32. Hoover, W. L.; Melto, J. R.; Howard, P. A.; Bassett, J. W.; J. AOAC Int. 1974, 57, 18 .

33. Shaikh, A. U.; Tallman, D. E.; Anal. Chem. 1977, 49, 1093.

34. Maher, W. A.; At. Spectrosc. 1987, 8, 457

35. Maher, W. A.; Analyst 1983, 108, 305.

36. Maher, W. A.; Anal. Lett. 1983, 16, 801.

37. Tsalev, D. L.; Mandjukov, P. B.; Stratis, J. A.; J. Anal. At. Spectrom. 1987, $2,135$.

38. Hangen, J. A.; Lovett, R. J.; At. Spectrosc. 1986, 7, 69.

39. Korkmaz, D. K.; Ertas, N.; Ataman, O. Y.; Volume of Abstracts of the XXXII Colloquium Spectroscopicum Internationale, Pretoria, South Africa, 2001.

40. Matusiewicz, H.; Sturgeon, R. E.; Spectrochim. Acta, Part B 1996, 51, 377.

41. Welz, B.; Sperling, M.; Atomic Absorption Spectrometry, $3^{\text {th }}$ ed., Wiley VCH Verlag GmbH, Weinheim: Germany, 1999.

42. Kahn, H. L.; Schallis, J. E.; At. Absorption Newsl. 1968, 7, 5.

43. Dalton, E. F.; Malonoski, A. J.; At. Absorption Newsl. 1971, 10, 92.

44. Fernandez, F. J.; Manning, D. C.; At. Absorption Newsl. 1971, 10, 86

45. Orheim, R. M.; Bovee, H. H.; Anal. Chem. 1974, 46, 921.

46. Walker, H. H.; Runnels, J. H.; Merryfield, R. N.; Anal. Chem. 1976, 48, 2056.

47. Hershey, J. W.; Keliher, P. N.; Spectrochim. Acta, Part B 1986, 41, 713.

48. Thompson, K. C.; Thomerson, D. R.; Analyst 1974, 99, 595.

49. Astron, O.; Anal. Chem. 1982, 54, 190.

50. Pettersson, J.; Hansson, L.; Olin, A.; Talanta 1986, 33, 49.

51. Welz, B.; Melcher, M.; Spectrochim. Acta, Part B 1981, 36, 439.

52. Verlinden, M.; Baart, J.; Deelstra, H.; Talanta 1980, 27, 633.

53. Dedina, J.; Prog. Anal. Spectrosc. 1988, 11, 251.

54. Hon, P-K.; Lau, O-W.; Tsui, S-K.; J. Anal. At. Spectrom. 1986, 1, 125.

55. Crock, J. G.; Lichte, F. E.; Anal. Chim. Acta 1982, 144, 223.

56. Siemer, D. D.; Hagemann, L.; Anal. Lett. 1975, 8, 323.

57. Lajunem, L. H. J.; Merkkiniemi, T.; Hayrynen, H.; Talanta 1984, 31, 709.

58. Balls, P. W.; Anal.Chim.Acta 1987, 197, 309.

59. Seimer, D. D.; Koteel, P.; Jariwala, V.; Anal. Chem. 1976, 48, 836. 
60. Seimer, D. D.; Koteel, P.; Anal. Chem. 1977, 49, 1096.

61. Andreae, M. O.; Asmode, J-F.; Foster, P.; Van’t dack, L.; Anal.Chem. 1987, 53, 1766.

62. Dedina, J.; Anal. Chem. 1982, 54, 2097.

63. Cutter, G. A.; Anal .Chim.Acta 1978, 98, 59

64. Cutter, G. A.; Anal. Chim. Acta 1983, 149, 391.

65. Andreae, M. O.; Anal. Chem. 1977, 49, 820.

66. Nakashima, S.; Analyst 1978, 103, 1031.

67. Dedina, J.; Matousek, T.; J. Anal. At. Spectrom. 2000, 15, 301.

68. Dedina, J.; Matousek, T.; Selecka, A.; Volume of Abstracts of the XXXII Colloquium Spectroscopicum Internationale, Pretoria, South Africa, 2001.

69. Grinberg, P.; Takase, I.; Campos, R. C.; J. Anal. At. Spectrom. 1999, 14, 827.

70. Knudson, E. J.; Christian, G. D.; At. Absorption Newsl. 1974, 13, 223.

71. McDaniel, M.; Shendrikar, A. D.; Reiszner, K.; West, P. W.; Anal. Chem. 1976, 48, 2240.

72. Lee, D.S.; Anal. Chem. 1982, 54,1682

73. Zhang, L.; Ni, Z.M.; Shan, X.Q.; Spectrochim. Acta, Part B 1989, 44, 339.

74. Zhang, L.; Wang, Y.; Wang, X.; Feng, J.; Talanta 1995, 42,1095.

75. Sinemus, H. W.; Kleiner, J.; Stabel, H. H.; Radziuk, B.; J. Anal. At. Spectrom. 1992, 7, 433.

76. Sturgeon, R. E.; Willie, S. N.; Sproule, G. I.; Robinson, P. T.; Berman, S. S.; Spectrochim. Acta, Part B 1989, 44, 667.

77. Li, Z.; Zhe-Ming, N.; Xiao-Quan, S.; Spectrochim. Acta, Part B 1989, 44, 751 .

78. Ni, Z-M.; Han, H-B.; Li, A.; Xu, F-Z.; J. Anal. At. Spectrom. 1991, 6, 385.

79. Sturgeon, R. E.; Willie, S. N.; Bermann, S. S.; Fresenius' J. Anal. Chem. 1986, 323,788 .

80. Akman, S.; Genc, O.; Balkis, T.; Spectrochim. Acta, Part B 1982, 37, 903.

81. Sturgeon, R. E.; Willie, S. N.; Berman, S. S.; Anal. Chem. 1985, 57, 2311.

82. Andreae, M. O.; Anal. Chem. 1984, 56, 2064.

83. Sturgeon, R. E.; Willie, S. N.; Berman, S. S.; J. Anal. At. Spectrom. 1986, 1,115 .

84. Willie, S. N.; Sturgeon, R. E.; Berman, S. S.; Anal. Chem. 1986, 58, 1140. 85. Willie, S. N.; Spectrochim. Acta, Part B 1996, 51, 1781.

86. Aroza, I.; Bonilla, M.; Madrid, Y.; Cámara-Rica, C.; J. Anal. At. Spectrom. 1989, 4,163 .

87. Thompson, K. C.; Analyst 1975, 100, 307.

88. Tsujii, K.; Kuga, K.; Anal. Chim. Acta 1974, 72, 85.

89. Barra, C. M.; Santelli, R. E.; Abrão, J. J.; de la Guardia, M.; Quim. Nova 2000, 23, 58 .

90. Thompson, M.; Pahlavanpour, B.; Walton, S. J.; Kirkbright, G. F.; Analyst 1978, 103, 568 .

91. Thompson, M.; Pahlavanpour, B.; Walton, S. J.; Kirkbrigth, G. F.; Analyst 1978, 103, 705 .

92. Lichte, F. E.; Skoberboe, R. K.; Anal. Chem. 1972, 44, 1480.

93. Wennrich, R.; Dittrich, K.; Franz, T.; Spectrochim. Acta, Part B 1994, 49, 1695 .

94. Wennrich, R.; Dittrich, K.; Franz, T.; Spectrochim. Acta, Part B 1995, 50, 1655 .

95. Matusiewicz, H.; Sturgeon, R. E.; Spectochim. Acta, Part B 1996, 51, 377.

96. Sturgeon, R. E., Gregoire, D. C.; Spectrochim. Acta, Part B 1994, 49, 1335.

97. Welz, B.; Melcher, M.; Analyst 1983, 108, 213.

98. Bax, D.; van Elteren, J. T.; Agterdenbos, J.; Spectrochim. Acta, Part B 1986, 41, 1007.

99. Bax, D.; Peters, F. F.; van Noort, J. P. M.; Agterdenbos, J.; Spectrochim. Acta, Part B 1986, 41, 275.

100. Parisis, N. E.; Heyndrickx, A.; Analyst 1986, 111, 281.

101. Evas, W. H.; Jackson, F. J.; Dellar, D.; Analyst 1986, 104, 16.

102. Narsito, A. J.; Anal. Chim. Acta 1987, 197, 315.

103. Wang, W-J.; Hanamura, S.; Winefordner, J. D.; Anal. Chim. Acta 1986, 184, 213

104. Shaikl, A. U.; Tallman, D. E.; Anal. Chim. Acta 1978, 98, 251.

105. Drittrich, K.; Mandry, R.; Udelnow, Ch.; Udelnow, A.; Fresenius' J. Anal. Chem. 1986, 323, 793 .

106. Sturgeon, R. E.; Willie, S. N.; Sproule, G. I.; Berman, S. S.; J. Anal. At. Spectrom. 1987, 2, 719.

107. Tanaka, S.; Nakamura, M.; Yokoi, H.; Yumura, M.; Hashimoto, Y.; Bunseki Kagaku 1986, 35, 116.

108. Yamamoto, M.; Yasuda, M.; Yamamoto, Y.; Anal. Chem. 1985, 57, 1382.

109. de Doncker, K.; Dumarey, R.; Dams, R.; Hoste, J.; Anal. Chim. Acta 1983, $153,33$.

110. Donaldson, E. M.; Leaver, M. E.; Talanta 1988, 35, 297.

111. Fiorino, J. A.; Jones, J. W.; Capar, S. G.; Anal. Chem. 1976, 48, 120.

112. Pahlavanpour, B.; Pullen, J. H.; Thompson, M.; Analyst 1980, 105, 274.

113. Maher, W. A.; Talanta 1982, 29, 532

114. Schmidt, J. F.; Royer, J. L.; Anal. Lett. 1973, 6, 17.
115. Haring, B. J. A.; van Delft, W.; Bom, C. M.; Fresenius' J. Anal. Chem. 1982, 310, 217

116. Apte, S. C.; Howard, A. G.; J. Anal. At. Spectrom. 1986, 1, 379.

117. Piwonka, J.; Kaiser, G.; Toelg, G.; Fresenius' J. Anal. Chem. 1985, 321, 225 .

118. Cutter, G. A.; Anal. Chem. 1985, 57, 2951.

119. Krivan, V.; Petrick, K.; Welz, B.; Melcher, M.; Anal. Chem. 1985, 57, 1703.

120. Nakata, F.; Yasui, Y.; Matsuo, H.; Kumamaru, T.; Anal. Sci. 1985, 3, 417.

121. Welz, B.; Melcher, M.; Anal. Chim. Acta 1981, 131, 168.

122. Apte, S. C.; Howard, A. G.; J. Anal. At. Spectrom. 1986, 1, 221.

123. Cleuvenbergen, R. J. A. Van; Van Mol, F. C.; Adams, F. C.; J. Anal. At. Spectrom. 1988, 3, 169.

124. Hambrick, G. A.; Froelich, P. N. Jr.; Andraea, M. O.; Lewis, B. L.; Anal. Chem. 1984, 56, 421.

125. Donard, F. X.; Int. J. Environ. Anal. Chem. 1986, 27, 184.

126. Han, J. S.; Weber, J. H.; Anal. Chem. 1988, 60, 316.

127. Donard, F. X.; Rapsomanikis, S.; Weber, J. H.; Anal. Chem. 1986, 58, 772

128. Quináia, S. P.; Dissertação de Mestrado,Universidade Estadual de Maringá, Paraná, Brasil, 1996.

129. Smith, A. E.; Analyst 1975, 100, 300.

130. Bax, D.; Agterdenbos, J.; Worrell, E.; Kolmer, J. B.; Spectrochim. Acta, Part B 1988, 43, 1349 .

131. Landsberger, S.; Boswell, G. G. J.; Anal. Chim. Acta 1977, 89, 281.

132. Meyer, A.; Hofer, Ch.; Tölg, G.; Raptis, S.; Knapp, G.; Fresenius' J. Anal. Chem. 1979, 296, 337

133. Fleming, H. D.; Ide, R. G.; Anal. Chim. Acta 1976, 83, 67.

134. Pierce, F. D.; Brown, H. R.; Anal. Chem. 1977, 49, 1417.

135. Futekov, L.; Angelova, G.; Specker, H.; Fresenius' J. Anal. Chem. 1979, $294,262$.

136. Workman, S. M.; Soltanpour, P. N.; Soil Sci. Soc. Am. J. 1980, 44, 133.

137. Roden, D. R.; Tallman, D. E.; Anal. Chem. 1982, 54, 307.

138. Drittrich, K.; Mandry, R.; Analyst 1986, 111, 269.

139. Drittrich, K.; Mandry, R.; Analyst 1985, 111, 277.

140. Verlinden, M.; Dulstra, H.; Fresenius'J. Anal. Chem. 1979, 296, 253.

141. Agterdenbos, J.; van Noort, J. P. M.; Peters, F. F.; Bax. D.; Ter Heege, J. P.; Spectrochim. Acta, Part B 1985, 40, 501.

142. Welz, B.; Melcher, M.; Analyst 1984, 109, 569.

143. Inui, T.; Terada, S.; Tamura, H.; Ichinose, N.; Fresenius' J. Anal. Chem. 1983, 315,598 .

144. Welz, B.; Melcher, M.; Analyst 1984, 109, 573.

145. Welz, B.; Schubert-Jacobs, M.; J. Anal. At. Spectroc. 1986, 1, 23.

146. Yamomoto, M.; Yamomoto, Y.; Yamashige, T.; Analyst 1984, 109, 1461.

147. Soria, M. T. M.; Asensio, J. S.; Bernal, J. G.; J. Anal. At. Spectroc. 1995, 10,975

148. Kos, V.; Veber, M.; Hudnik, V.; Fresenius'J. Anal. Chem. 1998, 360, 225.

149. Yuam, Y.; Guo, X.; Tong, K.; Fenxi Huaxue 1998, 26, 259.

150. Tsalev, D. L.; Sperling, M.; Welz. B.; Analyst 1992, 117, 1729.

151. Welz, B.; Melcher, M.; Anal. Chim. Acta 1983, 153, 297.

152. Inui, T.; Terada, S.; Tamura, H.; Ichinose, N.; Fresenius' J. Anal. Chem. 1982, 311, 492

153. Feng, X. J.; Fu, B.; Anal. Chim. Acta 1998, 371, 109

154. Ding, W-W.; Sturgeon R. E.; J. Anal. At. Spectroc. 1996, 11, 421.

155. Brockmann, A.; Nonn, C.; Golloch, A.; J. Anal. At. Spectroc. 1993, 8, 397.

156. Halicz, L.; Analyst 1985, 110, 943.

157. Bye, R.; Anal. Chim. Acta 1988, 208, 347.

158. Takase, I.; Luna, A. S.; Campos, R. C.; Resumos da 24a. Reunião Anual da Sociedade Brasileira de Química, Poços de Caldas, Brasil, 2001.

159. Takase, I.; Grinberg, P.; Campos, R. C.; Volume of Abstracts of the XXXII Colloquium Spectroscopicum Internationale, Pretoria, South Africa, 2001.

160. Takase, I.; Grinberg, P.; Luna, A. S.; Campos, R. C.; Spectrochim. Acta Part B. 2002, 57, 463.

161. Kobayashi, S.; Nakahara, T.; Musha, S.; Talanta 1979, 26, 951.

162. Nakahara, T.; Kobayashi, S.; Musha, S.; Anal. Chem. 1979, 51, 1589.

163. Muñoz, O.; Vélez, D.; Cervera, M. L.; Montoro, R.; J. Anal. At. Spectrom. 1999, 14, 1607

164. Vélez, D.; Ybáñez, N.; Montoro, R.; J. Anal. At. Spectrom. 1997, 12, 91.

165. Muñoz, O.; Vélez, D.; Montoro, R.; Analyst 1999, 124, 601.

166. Fedorov, P. N.; Ryabchuk, G. N.; Zverev, A. V.; Spectrochim. Acta, Part B 1997, 52, 1517

167. Featherstone, A. M.; Butler, E. C. V.; O’Grady, B. V.; Michel. P.; J. Anal. At. Spectrom. 1998, 13, 1355

168. Moreda-Piñeiro, J.; Cervera, M. L.; Guardia, M.; J. Anal. At. Spectrom. 1997, 12, 1377.

169. Magnuson, M. L.; Creed, J. T.; Brockhoff, C. A.; J. Anal. At. Spectrom. 1997, 12, 689 .

170. Liang, L.; Lazoff, S.; Chan, C.; Horvat, M.; Woods, J. S.; Talanta 1998, 47,569 
171. Karthikeyan, S.; Rao, T. P.; Iyer, C. S. P.; Talanta 1999, 49, 523

172. Müller, J.; Fresenius' J. Anal. Chem. 1999, 363, 572.

173. Bermejo-Barrera, P.; Moreda-Piñeiro, J.; Moreda-Piñeiro, A.; BermejoBarrera, A.; Anal. Chim. Acta 1998, 368, 281.

174. Bermejo-Barrera, P.; Ferrón-Novais, M.; González-Campos, G.; BermejoBarrera, A.; At. Spectrosc. 1999, 20, 120.

175. Narasaki, H.; Hou, H-B.; Anal. Sci. 1999, 15, 911.

176. Hou, H-B.; Narasaki, H.; At. Spectrosc. 1999, 20, 20.

177. Hou, H-B.; Narasaki, H.; At. Spectrosc. 1998, 19, 23.

178. He, Y.; Moreda-Piñeiro, J.; Cervera, M. L.; Guardia, M.; J. Anal. At. Spectrom. 1998, 13, 289.

179. Flores, E. M. M.; Mortari, S. R.; Martins, A. F.; J. Anal. At. Spectrom. 1997 12,379 .

180. Cabon, J. Y.; Erler, W.; Analyst 1998, 123, 1565.

181. Wei, M-T.; Jiang, S-L.; J. Anal. At. Spectrom. 1999, 14, 1177.

182. Lam, J. W.; Sturgeon, R. E.; At. Spectrosc. 1999, 20, 79.

183. Bowman, J.; Fairman, B.; Catterick, T.; J. Anal. At. Spectrom. 1997, 12, 313.

184. Santosa, S. T.; Mokudai, H.; Tanaka, S.; J. Anal. At. Spectrom. 1997, 12 , 409.

185. Elfering, H.; Andersson, J. T.; Poll, R. G.; Analyst 1998, 123, 669.

186. Damkröger, G.; Grote, M.; Janben, E.; Fresenius'J. Anal. Chem. 1997, 357, 817 .

187. Matusiewicz, H.; Kopras, M.; Sturgeon, R. E.; Analyst 1997, 122, 331.

188. Moreno, M. E.; Perez-Conde, C.; Cámara, C.; J. Anal. At. Spectrom. 1998, $13,1181$.

189. Krachler, M.; Burow, M.; Emons, H.; Analyst 1999, 124, 923.

190. Feng, Y-L.; Narasaki, H.; Chen, H.-Y.; Tian, L.-C.; Fresenius' J. Anal. Chem. 1997, 357, 822.

191. Messerschmidt, J.; Von Bohlen, A.; Alt, F.; Klockenkämper, R.; J. Anal. At. Spectrom. 1997, 12, 1251.

192. Liversage, R. R.; Van Loon, J. C.; Andrade, J. C.; Anal. Chim. Acta 1984 $161,275$.

193. Vargas-Razo, C.; Tyson, J. F.; Fresenius' J. Anal. Chem. 2000, 366, 182.

194. Wei, L.; Gupta, P.; Hernandez, R.; Farhat, F.; Microchem. J. 1999, 62, 83.

195. Dong, X.; Nakaguchi, Y.; Hiraki, K.; Anal. Sci. 1997, 13, 195.

196. Keenan, F.; Cooke, C.; Cooke, M.; Pennock, C.; Anal. Chim. Acta 1997, 354,1 .

197. Tsalev, D. L.; Sperling, M.; Welz, B.; Analyst 1998, 123, 1703.

198. Ng, J. C.; Johnson, D.; Imray, P.; Chiswell, B.; Moore, M. R.; Analyst 1998 $123,929$.

199. Sur, R.; Begerow, J.; Dunemann, L.; Fresenius'J. Anal. Chem. 1999, 363, 526.

200. Ritsema, R.; Van Heerde, E.; Fresenius' J. Anal. Chem. 1997, 358, 838.

201. Guo, T.; Baasner, J.; Tsalev, D. L.; Anal. Chim. Acta 1997, 349, 313.

202. Cadore, S.; Anjos, A. P.; Baccan, N.; Analyst 1998, 123, 1717.

203. Tyson, J. F.; Sundin, N. G.; Hanna, C. P.; McIntosh, S. A.; Spectrochim. Acta, Part B 1997, 52, 1773.

204. Gómez, M. M.; Gasparic, T.; Palacios, M. A.; Cámara, C.; Anal. Chim. Acta 1998, 374, 241.

205. Li, F.; Goessler, W.; Irgolic, K. J.; Anal. Comm. 1998, 35, 361.

206. Wifladt, A-M.; Wibetoe, G.; Lund, W.; Fresenius' J. Anal. Chem. 1999 357, 92.

207. Segura, M.; Madrid, Y.; Cámara, C.; J. Anal. At. Spectrom. 1999, 14, 131.

208. Chen, H-Y.; Chen, H-W.; Feng, Y-L.; Tian, L-C.; At. Spectrosc. 1997, 18 , 29.

209. Cadore, S.; Baccan, N.; J. Anal. At. Spectrom. 1997, 12, 637.

210. Feng, X. J.; Fu, B.; Anal. Chim. Acta 1998, 371, 109.

211. Mierzwa, J.; Adeloju, S. B.; Dhindsa, H. S.; Analyst 1997, 122, 539.

212. Kowalewska, Z.; Bulska, E.; Hulanicki, A.; At. Spectrosc. 1997, 18, 160.

213. Martín-García, M. B.; Bellido-Milla, D.; Jimenez-Jimenez, A.; HernándezArtiga, M. P.; Fresenius'J. Anal. Chem. 1999, 364, 527.

214. Krachler, M.; Burow, M.; Emons, H.; Analyst 1999, 124, 777.

215. Barra, C. M.; Cervera, M. L.; Guardia, M.; Santelli, R.; Anal. Chim. Acta 2000, 407, 155

216. Kos, V.; Veber, M.; Hudnik, V.; Fresenius' J. Anal. Chem. 1998, 360, 225.

217. Mierzwa, J.; Dobrowolski, R.; Spectrochim. Acta, Part B 1998, 53, 117.

218. Zhou, C. Y.; Wong, M. K.; Koh, L. L.; Mikrochim. Acta 1997, 127, 77.

219. Feng, Y-L.; Chen, H-Y.; Chen, H-W.; Tian, L-C.; Fresenius' J. Anal. Chem. 1998, 361, 155

220. Hall, G. E. M.; Pelchat, J-C.; J. Anal. At. Spectrom. 1997, 12, 97.

221. De-quian, Z.; Han-wen, S.; Li-li, Y.; Fresenius' J. Anal. Chem. 1997, 359, 492.

222. Gámiz-García, L.; Castro, M. D. L.; Talanta 1999, 50, 693.

223. Moor, C.; Lam, J.; Sturgeon, R. E.; J. Anal. At. Spectrom. 2000, 15, 143.

224. Emteborg, H.; Baxter, D. C.; Ellingsen, D.; Frech, W.; Thomassen, Y.; Analyst 1992, 117, 657
225. Emteborg, H.; Baxter, D. C.; Frech, W.; Analyst 1993, 118, 1007.

226. Emteborg, H.; Baxter, D. C.; Sharp, M.; Frech, W.; Analyst 1995, 120, 69

227. Hanstrom, S.; Briche, C.; Emteborg, H.; Baxter, D. C.; Analyst 1996, 121, 1657.

228. Snell, J. P.; Frech, W.; Thomassen, Y.; Analyst 1996, 121, 1055.

229. Fijuwara, K.; Okamoto, Y.; Ohno, M.; Kumamaru, T.; Anal. Sci. 1995, 11, 829.

230. Lobinski, R.; Adams, F. C.; J. Anal. At. Spectrom. 1992, 7, 987.

231. Heisterkamp, M.; Smaele, T.; Candelone, J.-P.; Moens, L.; Dams, R.; Adams, F. C.; J. Anal. At. Spectrom. 1997, 12, 1077.

232. Chau, Y. K.; Zhang, S.; Maguire, R. J.; Analyst 1992, 117, 1161.

233. Wong, P. T. S.; Chau, Y. K.; Brown, M.; Whittle, D. M.; Appl. Organomet. Chem. 1994, 8, 385.

234. Stäb, J. A.; Brinkman, U. A. Th.; Cofino, W. P.; Appl. Organomet. Chem. 1994, 8, 577

235. Fernandez, M. A. S.; Tese de Doutorado, Pontifícia Universidade Católica do Rio de Janeiro, Brasil, 2001.

236. Tao, S.; Kamamaru, T.; Anal. Chim. Acta 1995, 310, 369.

237. Okamoto, Y.; Fujiwara, K.; Kamamaru, T.; Anal. Sci. 1996, 12, 803.

238. Kamamaru, T.; Tao, S.; Uchida, M.; Okamoto, Y.; Anal. Lett. 1994, 27, 2331.

239. Mota, J. P. V.; de la Campa, M. R. F.; Sanz-Medel, A.; J. Anal. At. Spectrom. 1998, 13, 431 .

240. Hill, S. J.; J. Anal. At. Spectrom. 1993, 8, 723.

241. Váldez-Hevia, M. C. T.; de la Campa, M. R. F.; Sanz-Medel, A.; J. Anal. At. Spectrom. 1994, 9, 231.

242. D'Ulivo, A.; Chen, Y.; J. Anal. At. Spectrom. 1989, 4, 319.

243. Bloom, N.; Can. J. Fis. Aquat. Sci. 1989, 46, 1131.

244. Holz, J.; Kreutzmann, J.; Wilken, R.; Falter, R.; Appl. Organomet. Chem. 1999, 13, 789 .

245. Liang, L.; Horvat, M.; Bloom, N. S.; Talanta 1994, 41, 371.

246. Hintelmann, H.; Evans, R. D.; Villeneuve, J. Y.; J. Anal. At. Spectrom. 1995, 10,619 .

247. Tseng, C. M.; Diego, A.; Martin, F. M.; Donard, O. F. X.; J. Anal. At. Spectrom. 1997, 12, 629.

248. Fisher, R.; Rapsomanikis, S.; Andreae, M. O.; Anal. Chem. 1993, 65, 763.

249. Gerbersmann, C.; Heisterkamp, M.; Adams, F. C.; Broekaert, J. A. C.; Anal. Chim. Acta 1997, 350, 273.

250. Pereiro, I. R.; Wasik, A.; Lobinski, R.; J. Anal. At. Spectrom. 1998, 13, 743.

251. Jimenez, M. S.; Sturgeon, R. E.; J. Anal. At. Spectrom. 1997, 12, 597.

252. Sturgeon, R. E.; Willie, S. N.; Berman, S. S.; Anal. Chem. 1989, 61, 1867.

253. Willie, S. N.; At. Spectrosc. 1994, 15, 205.

254. Witte, C.; Szpunar-Lobnska, J.; Lobinski, R.; Adams, F. C.; Appl. Organomet. Chem. 1994, 8, 621 .

255. de la Calle Guntiñas, M. B.; Lobinski, R.; Adams, F. C.; J. Anal. At. Spectrom. 1995, 10, 111

256. Ceukemans, C.; Szpunar-Lobinska, J.; Dirkx, W. M. R.; Lobinski, R.; Adams, F. C.; Int. J. Environ. Anal. Chem. 1993, 52, 113.

257. Ceulemans, M.; Witte, C.; Lobinski, R.; Adams, F. C.; Appl. Organomet. Chem. 1994, 8, 451.

258. Allabashi, R.; Rendl, J.; Grasserbauer, M.; Fresenius'J. Anal. Chem. 1998, $360,723$.

259. Szpunar, J.; Schmitt, V. O.; Lobinski, R.; Monod, J-L.; J. Anal. At. Spectrom. 1996, 11, 193.

260. Cai, Y.; Rapsomanikis, S.; Andreae, M. O.; J. Anal. At. Spectrom. 1993, 8, 119

261. Cai, Y.; Rapsomanikis, S.; Andreae, M. O.; Talanta 1994, 41, 589.

262. Szpunar, J.; Ceulemans, M.; Schmitt, V. O.; Adams, F. C.; Lobinski, R.; Anal. Chim. Acta 1996, 332, 225.

263. Adams, F. C.; Ceulemans, M.; J. Anal. At. Spectrom. 1996, 11, 201

264. Prange, A.; Jantzen, E.; J. Anal. At. Spectrom. 1995, 10, 105.

265. Adams, F. C.; Heisterkamp, M.; J. Anal. At. Spectrom. 1999, 14, 1307.

266. Hempel, M.; Kuballa, J.; Jantzen, E.; Fresenius' J. Anal. Chem. 2000, 366, 470.

267. Hu, G.; Wang, X.; Wang, Y.; Chen, X.; Jia, L.; Anal. Lett. 1997, 30, 2579.

268. Sun, Y-C.; Mierzwa, J.; Chung, Y-T.; Yang, M-H.; Anal. Comm. 1997, 34, 333.

269. Tao, S.; Okamoto, Y.; Kamamaru, T.; Anal. Sci. 1995, 11, 319.

270. Okamoto, Y.; J. Anal. At. Spectrom. 1999, 14, 1631.

271. Heisterkamp, M.; Adams, F.; Fresenius'J. Anal. Chem. 1998, 362, 489

272. Rigin, V. I.; Zh. Anal. Khim. 1985, 40, 1399.

273. Rigin, V. I.; Zh. Anal. Khim. 1986, 41, 788.

274. Aggarwal, S. K.; Kinter, M.; Nicholson, J.; Herold, D. A.; Anal. Chem. 1994, 66, 1316

275. Motojima, K.; Tatenuma, K.; Yoshida, Z.; Takeishi, H.; Akatsu, E.; Anal. Chim. Acta 1986, 183, 217. 
276. Tao, H.; Miyazaki, A.; Bansho, K.; Anal. Chem. 1988, 60, 1762.

277. Tesfalidet, S.; Irgum, K.; Anal. Chem. 1988, 60, 2031.

278. Guo, X.-W.; Guo, X.-M.; Anal. Chim. Acta 1996, 330, 237.

279. Smichowski, P.; Farias, S.; J. Anal. At. Spectrom. 1999, 14, 809.

280. Kuznetsov, L. B.; Kolonina, L. N.; Belyaev, V. N.; Zh. Anal. Khim. 1986, 41,80 .

281. Lopez-Molinero, A.; Castillo, J. R.; Chamorro, Pascual, P.; Callizo, A.; Mikrochim. Acta 1999, 131, 225

282. Rigin, V. I.; Zh. Anal. Khim. 1985, 40, 630.

283. Rigin, V. I.; Zh. Anal. Khim. 1986, 41, 581

284. Lopez- Molinero, A.; Benito, M.; Aznar, Y.; Villareal, A.; Castillo, J. R.; J. Anal. At. Spectrom. 1998, 13, 215.

285. Lopez-Molinero, A.; Martinez, L.; Villareal, A.; Castillo, J. R.; Talanta 1998, 45, 1211.

286. Vijan, P. N.; At. Spectrosc. 1980, 1, 143.

287. Lee, D. S.; Anal. Chem. 1982, 54, 1162.

288. Erber, D.; Cammann, K.; Analyst 1995, 120, 2699.

289. Park, C. J.; Yim, S.; J. Anal. At. Spectrom. 1999, 14, 1061.

290. Uthus, E. O.; Collings, M. E.; Cornatzer, W. E.; Nielsen, F. H.; Anal. Chem. 1981, 53, 2221.
291. Masahito, I.; Anal. Chim. Acta 1985, 167, 287.

292. Kirkbright, G. F.; Taddia, M.; Anal. Chim. Acta 1978, 100, 145.

293. Welz, B.; Sucmanova, M.; Analyst 1992, 118, 1417.

294. Wickstron, T.; Lund, W.; Bye, R.; Analyst 1992, 118, 1425.

295. Nakahara, T.; Kikui, N.; Anal. Chim. Acta 1985, $172,127$.

296. Burns, D. T.; Chimpalee, N.; Harriott, M.; Anal. Chim. Acta 1995, 311,

93

297. Drinkwater, J. E.; Analyst 1976, 101, 672.

298. Takada, T.; Fujita, K.; Talanta 1985, 32, 571.

299. Takase, I.; Campos, R. C.; Talanta 2000, 51, 441.

300. Takase, I.; Campos, R. C.; Volume of Abstracts of the Fifth Rio Symposium on Atomic Spectrometric, Cancun, México, 1998.

301. de Doncker, K.; Dumarey, R.; Dams, R.; Hoste, J.; Anal. Chim. Acta 1985, $169,339$.

302. Takase, I.; Luna, A. S.; Campos, R. C.; Livro de Resumos do $11^{0}$ Encontro Nacional de Química Analítica, Campinas, Brasil, 2001.

303. Wickstron, T.; Lund, W.; Bye, R.; J. Anal. At. Spectrom. 1991, 6, 389.

304. Bye, R.; Analyst 1985, 110, 85.

305. Abdallah, A. M.; J. Anal. At. Spectrom. 1993, 8, 759.

306. Wickstron, T.; Lund, W.; Bye, R.; Analyst 1995, 120, 2695. 